\title{
Presupposed free choice and the theory of scalar implicatures
}

\author{
Paul Marty ${ }^{1}$ (D) Jacopo Romoli ${ }^{2}$
}

Accepted: 10 October 2020 / Published online: 19 May 2021

(c) The Author(s) 2021

\begin{abstract}
A disjunctive sentence like Olivia took Logic or Algebra conveys that Olivia didn't take both classes (EXCLUSIVITY) and that the speaker doesn't know which of the two classes she took (IGNORANCE). The corresponding sentence with a possibility modal, Olivia can take Logic or Algebra, conveys instead that she can take Logic and that she can take Algebra (FREE CHOICE). These EXCLUSIVITY, IGNORANCE and FREE CHOICE inferences are argued by many to be scalar implicatures. Recent work has looked at cases in which EXCLUSIVITY and IGNORANCE appear to be computed instead at the presupposition level, independently from the assertion. On the basis of those data, Spector and Sudo (Linguist Philos 40(5):473-517, 2017) have argued for a hybrid account relying on a pragmatic principle for deriving implicatures in the presupposition. In this paper, we observe that a sentence like Noah is unaware that Olivia can take Logic or Algebra has a reading on which FREE CHOICE appears in the presupposition, but not in the assertion, and we show that deriving this reading is challenging on Spector and Sudo's (2017) hybrid account. Following the dialectic in Fox (Presupposition and implicature in compositional semantics, Palgrave, London, pp 71-120, 2007), we argue against a pragmatic approach to presupposition-based implicatures on the ground that it is not able to account for presupposed free choice. In addition, we raise a novel challenge for Spector and Sudo's (2017) account coming from the conflicting presupposed IGNORANCE triggered by sentences like \#Noah is unaware that I have a son or a daughter, which is infelicitous even if it's not common knowledge whether the speaker has a son or a daughter. More generally, our data
\end{abstract}

For very helpful discussion and feedback, we would like to thank Sam Alxatib, Richard Breheny, Moysh Bar-Lev, Itai Bassi, Gennaro Chierchia, Danny Fox, Simon Goldstein, Matt Mandelkern, Paolo Santorio, Uli Sauerland, Philippe Schlenker, Benjamin Spector, Yasu Sudo and audiences at UCL, the University of Maryland, and MIT. This work was supported by the Leverhulme Trust Grant RPG-2018-425.

$\bowtie \quad$ Paul Marty

p.marty@ucl.ac.uk

1 Division of Psychology and Language Sciences, University College London, Chandler House, 2 Wakefield Street, London WC1N 1PF, England, UK

2 Department of Foreign Languages, University of Bergen, Postbox 7805, 5020 Bergen, Norway 
reveals a systematic parallelism between the assertion and presupposition levels in terms of EXCLUSIVITY, IGNORANCE, and FREE CHOICE. We argue that such parallels call for a unified analysis and we sketch how a grammatical theory of implicatures where meaning strengthening operates in a similar way at both levels (Gajewski and Sharvit in Nat Lang Semant 20(1):31-57, 2012; Magri in A theory of individuallevel predicates based on blind mandatory scalar implicatures, MIT dissertation, 2009; Marty in Implicatures in the DP domain, MIT dissertation, 2017) can account for such parallels.

Keywords Free choice disjunction · Exclusivity · Ignorance $\cdot$ Presupposition · Scalar implicature · Exhaustification

\section{Introduction}

A disjunctive sentence like (1) has long been observed to give rise to two types of inferences: the exclusivity inference in (1-a), conveying that the speaker doesn't believe that both disjuncts are true, and the ignorance inference in (1-b), conveying that the speaker is ignorant about which disjunct is true.

(1) Olivia took Logic or Algebra.

a. $\leadsto$ Olivia didn't take both Logic and Algebra

EXCLUSIVITY

b. $\sim$ The speaker doesn't know which of the two classes she took IGNORANCE

The corresponding sentence with a possibility modal, illustrated in (2), gives rise to another type of inference, usually referred to as 'free choice.' That is, it conveys that Olivia can take Logic and that she can take Algebra, and thus that she can choose between the two (von Wright 1968; Kamp 1974 and much subsequent work). The EXCLUSIVITY, IGNORANCE and FREE CHOICE inferences above have all been argued to be scalar implicatures. ${ }^{1}$

(2) Olivia can take Logic or Algebra.

$\sim$ Olivia can choose between the two classes

FREE CHOICE

There are two main approaches to scalar implicatures. The first, the 'Neo-Gricean' approach, builds on Grice's (1975) original characterisation of implicatures as inferences arising from implicit reasoning in rational interactions. ${ }^{2}$ On this approach, implicatures arise from the hearer's reasoning about what the speaker said and could have said instead. This approach provides a unified analysis of the inferences in (1) as implicatures in that sense. The second approach, generally referred to as the 'Grammatical' approach, argues instead that implicatures arise from the composi-

\footnotetext{
1 While this is relatively uncontroversial in the case of EXCLUSIVITY and IGNORANCE inferences, it is a matter of debate for FREE CHOICE. We will come back to this point below. For an implicature approach to FREE CHOICE and relevant discussion see Fox (2007), Chemla (2010), Klinedinst (2007), Franke (2011), Santorio and Romoli (2017), Bar-Lev and Fox (2020), Bar-Lev (2018) among others.

2 Horn (1972), Gazdar (1979), Sauerland (2004), Schulz and Van Rooij (2006), Spector (2006), Geurts (2010), Chemla (2010), Franke (2011) among others.
} 
tional calculation of meaning. ${ }^{3}$ A common implementation of this approach involves a covert exhaustivity operator in the syntax, the meaning of which gives rise to the exclusivity implicature in (1-a). Some versions of this approach maintains that the ignorance implicature in (1-b) arises through pragmatic reasoning (e.g., Fox 2007), while others derive them in the grammar as well by making use of an additional epistemic operator (e.g., Meyer 2013; Buccola and Haida 2019).

Both the pragmatic and grammatical approaches to scalar implicature can readily derive EXCLUSIVITY and IGNORANCE inferences. However, as Fox (2007) has extensively discussed, deriving FREE CHOICE is challenging for the pragmatic approach, while it is relatively unproblematic for the grammatical one. On the basis of these observations, Fox has argued that, to the extent that free choice is to be treated as an implicature, it constitutes an argument in favour of the grammatical approach. ${ }^{4}$

With this background in mind, let us turn to a recent line of work that has investigated cases where implicatures interact with factive presuppositions. Specifically, this line of research has looked at cases where implicatures appear to be computed in the presupposition but not in the assertion, a 'presupposed implicature' henceforth. ${ }^{5}$ For instance, it has been observed that a sentence like (3) has a reading on which an implicature only appears in the presupposition. On this reading, (3) conveys that it's not true that, according to Noah, some students took Logic, (3-a), while at the same time suggesting that some but not all of them took Logic, the plain presupposition in (3-b) enriched with the implicature in (3-c) (a.o., Gajewski and Sharvit 2012; Spector and Sudo 2017).

(3) Noah is unaware that some of the students took Logic.
a. ASSERTION
Noah doesn't believe that any of the students took Logic
b. PRESUPPOSITION
Some of the students took Logic
c. PRESUPPOSED IMPLICATURE
$\sim$ Not all of the students took Logic

Gajewski and Sharvit (2012) take (3) to be an argument for a unified grammatical account of implicatures at the presupposition and the assertion levels. Spector and Sudo (2017) have criticised this unified approach based on two novel observations. First, they note that a sentence like (3) is infelicitous in a context in which it is

\footnotetext{
3 Chierchia (2004), Fox (2007), Chierchia et al. (2012), Magri (2009), Chierchia (2013), Romoli (2012), Meyer (2013), Marty (2017), Bar-Lev and Fox (2020), Bar-Lev (2018) among others.

4 We note right away that two kinds of replies have been given to Fox's argument and that, in principle, both replies could extend to our own extension of Fox's argument below. The first is to argue that free choice inferences are not implicatures after all (see Bar-Lev 2018; Goldstein 2019; Franke 2011; Aloni 2018; Romoli and Santorio (2019) a.o. for discussion). The second is to argue that the pragmatic approach can after all derive free choice as an implicature (Franke 2011; but see Fox and Katzir 2019 for critical discussion). We leave these analytical options aside for now to focus instead on the consequences of the presuppositional data we discuss for an implicature approach to free choice. We will go back to discuss a non-implicature approach to free choice in Sect. 6.

5 Two other types of interactions have been discussed in the recent literature. The first is about how implicatures can influence presuppositions and related phenomena (see Mayr and Romoli 2016 for discussion). The second has to do with the role of implicatures in filtering presuppositions (see Romoli and Santorio 2019 for discussion). We will briefly discuss the latter case in the conclusion.
} 
common knowledge that all of the students took Logic, as in (4-a) (even when the scalar term is given prosodic prominence, indicated here using SMALL CAPS). Its positive counterpart, on the other hand, is more felicitous in that context if the scalar term is stressed, (4-b). This asymmetry is surprising and unaccounted for on Gajewski and Sharvit's (2012) unified approach.

(4) CONTEXT: It is common knowledge that all of the students took Logic.

a. \#Noah is unaware that SOME of the students took Logic.

b. Noah is aware that SOME of the students took Logic.

Second, Spector and Sudo (2017) observe that a sentence like (5), involving a disjunctive sentence as a factive complement, gives rise not only to a presupposed implicature of EXCLUSIVITY, (5-c), but also to inferences of presupposed IGNORANCE, (5-d). Specifically, Spector and Sudo (2017) observe that (5) gives rise to the inference that the interlocutors do not commonly believe either of the embedded disjuncts to be true and that, because of these inferences of ignorance, an utterance of (5) is felicitous only if neither of these disjuncts is common knowledge among the interlocutors. Here again, it is prima facie unclear how to account for these ignorance inferences on Gajewski and Sharvit's (2012) approach.

(5) Noah is unaware that Olivia took Logic or Algebra.

a. ASSERTION

Noah doesn't believe that Olivia took either one

b. PRESUPPOSITION

Olivia took Logic or Algebra

c. PRESUPPOSED EXCLUSIVITY

$\sim$ Olivia didn't take both Logic and Algebra

d. PRESUPPOSED IGNORANCE

$\leadsto$ It is not common knowledge that Olivia took Logic

$\leadsto$ It is not common knowledge that Olivia took Algebra

On the basis of those two problematic cases, Spector and Sudo (2017) propose an alternative hybrid account based on two distinct scalar strengthening mechanisms: they adopt a grammatical theory of implicatures for deriving scalar implicatures in the assertion, while positing an independent pragmatic principle for deriving weaker implicatures about what is common knowledge. As we discuss below, the interplay between those two strengthening mechanisms can account for the asymmetry in (4) as well as for the presupposed IGNORANCE inferences in (5).

In this paper, we add to the empirical landscape above two observations. First, we observe that, in addition to EXCLUSIVITY and IGNORANCE, FREE CHOICE can also arise at the presupposition level and, sometimes, at the presupposition level only. Thus for instance, a sentence like (6) has a reading conveying that it's not true that Noah believes that Olivia can take either class, (6-a), while suggesting that Olivia has free choice between the two, (6-c). Hence, in parallel to the EXCLUSIVITY inference in (5), the FREE CHOICE inference in (6) appears in the presupposition but not in the assertion. 
(6) Noah is unaware that Olivia can take Logic or Algebra.

a. ASSERTION

Noah doesn't believe that Olivia can take either one

b. PRESUPPOSITION

Olivia can take Logic or Algebra

c. PRESUPPOSED FREE CHOICE

$\sim$ Olivia can take Logic and she can take Algebra

Second, we observe that the IGNORANCE inferences arising at the presupposition level are stronger than discussed in Spector and Sudo (2017), and in fact of similar strength as those arising from asserted disjunctions. That is, we observe that, in parallel to (1), an utterance of (5) doesn't merely convey that it is not common knowledge which of the two classes Olivia took, but rather that the speaker is ignorant as to which of the two classes she took. While this fine-grained difference is hard to detect in cases like (5), the speaker-orientation of those ignorance inferences becomes obvious in cases like (7)-(8). In the (a)-sentences, the ignorance inferences that the speaker doesn't know whether Olivia has two or more children are compatible with the speaker not knowing much about Olivia's family. However, in the (b)-sentences, the corresponding ignorance inferences now contradict the common assumption that people are normally knowledgeable about their own families. The (b)-sentences are thus perceived as infelicitous, even in a context in which it is not common knowledge how many children the speaker actually has. ${ }^{6}$

(7) a. Olivia has two or more children.

b. \#I have two or more children.

a. Noah is unaware that Olivia has two or more children.

b. \#Noah is unaware that I have two or more children.

We show that these novel observations are problematic for Spector and Sudo (2017). First, the presupposed ignorance inferences which can be derived in their system are too weak to account for cases like (8). Second, deriving the presupposed free choice reading of (6) in their system is challenging: allowing this inference to be derived from the working of their exhaustivity operator leads to over-generation issues for cases similar to (5) while deriving this inference with the pragmatic side of their system is challenging for the same reasons as deriving regular free-choice inferences is challenging for a pragmatic approach to assertion-based implicatures. In that respect, our dialectic will closely follows that of Fox (2007): we will argue against a pragmatic approach to presupposition-based implicatures on the ground that it is not able to account for presupposed free choice.

More generally, we observe that these novel data reveal a systematic parallelism between the assertion and presupposition levels in terms of EXCLUSIVITY (9), FREE CHOICE (10), and IGNORANCE inferences (11).

\footnotetext{
6 Both examples become, of course, felicitous in a context in which there are reasons to believe that the speaker could be ignorant about such personal facts (e.g., a case of amnesia).
} 
(9) Exclusivity and Presupposed Exclusivity

a. Olivia took Logic or Algebra. $\leadsto$ Olivia didn't take both Logic and Algebra

b. Noah is unaware that Olivia took Logic or Algebra. $\sim$ Olivia didn't take both Logic and Algebra

(10) Free Choice and Presupposed Free Choice

a. Olivia is allowed to take Logic or Algebra. $\sim$ Olivia can take Logic and she can take Algebra

b. Noah is unaware that Olivia is allowed to take Logic or Algebra. $\sim$ Olivia can take Logic and she can take Algebra

\section{(11) Ignorance and Presupposed Ignorance}

a. Olivia took Logic or Algebra.

$\sim$ The speaker doesn't know which of the two classes Olivia took

b. Noah is unaware that Olivia took Logic or Algebra.

$\sim$ The speaker doesn't know which of the two classes Olivia took

We argue that a grammatical theory of implicatures where meaning strengthening operates in a similar way at the assertion and presupposition levels (Gajewski and Sharvit 2012; Magri 2009; Marty 2017) can account for this parallelism and provide a unified analysis of those inferences. In particular, we will show how this approach can directly account for presupposed EXCLUSIVITY and presupposed FREE CHOICE and, once combined with a grammatical account of ignorance inferences à la Meyer (2013), it can account for presupposed ignorance as well, while maintaining an account of the asymmetry in (4).

The rest of the paper is organised as follows. In Sect.2, we outline the pragmatic and grammatical approaches to scalar implicatures and describe the challenge that free choice raises for the former. We then move in Sect. 3 to present the phenomenon of presupposed scalar implicatures and sketch the grammatical account by Gajewski and Sharvit (2012) and Magri (2009) as well as the hybrid account by Spector and Sudo (2017). In Sect. 4, we present the novel data points involving presupposed free choice and presupposed ignorance, and we discuss the challenges they raise for Spector and Sudo's (2017) account. In Sect. 5, we move to outline a unified grammatical approach to assertion-based and presupposition-based implicatures which can address these challenges. In Sect. 6, we outline some other directions one could take to account for our novel data and the challenges we identified. Section 7 concludes.

\section{Free choice and scalar implicatures}

\subsection{Two main approaches to scalar implicatures}

Consider again the two types of implicatures arising from disjunctions like (1). As we already mentioned, there are two main approaches to those implicatures in the 
literature: the Neo-Gricean pragmatic approach and the Grammatical approach. In the following, we sketch the gist of both approaches in turn.

(1) Olivia took Logic or Algebra.

a. EXCLUSIVITY

$\sim$ Olivia didn't take both Logic and Algebra

b. IGNORANCE

$\sim$ The speaker doesn't know which of the two classes Olivia took

Building on Grice's (1975) seminal work, the Neo-Gricean approach is based on the hypothesis that implicatures arise from the hearer reasoning about what the speaker said and what she could have said instead (a.o., Horn 1972; Gazdar 1979; Sauerland 2004; Schulz and Van Rooij 2006; Spector 2006; Geurts 2010; Chemla 2010; Franke 2011). Specifically, for what is most relevant for us, the hypothesis is that the hearer reasons under the assumption that the speaker obeys the Maxim of Quantity (MQ) in (12), which favours more informative statements over less informative ones when they are equally relevant to the topic of the conversation. ${ }^{7}$

\section{Maxim of Quantity (MQ)}

If $\phi$ and $\psi$ are both relevant to the topic of conversation, $\psi$ is more informative than $\phi$, and $\psi$ is among the alternatives of $\phi$, then, if the speaker believes that both are true, the speaker should prefer $\psi$ to $\phi$.

To illustrate how Quantity-based reasoning can derive the two implicatures above, consider first the EXCLUSIVITY implicature. Upon hearing (1), if the more informative and-alternative to (1) in (13) is relevant, the hearer will reason that the speaker should have preferred (13), had she believed it to be true. Therefore the hearer will conclude that it's not true that the speaker believes (13) on the basis of MQ.

Olivia took Logic and Algebra.

Assuming further that the speaker is opinionated as to whether (13) is true or false, the Opinionated Speaker (OS) assumption stated in (14) (adapted from Fox 2007), the hearer will strengthen the conclusion above to the belief that, according to the speaker, (13) is not true, deriving then the EXCLUSIVITY implicature in (1-a).

\section{Opinionated Speaker (OS)}

When a speaker $S$ utters a sentence, $\phi$, the addressee, $H$, assumes that $S$ 's beliefs determine the truth value of every alternative of $\phi$, unless this assumption leads to the conclusion that $S$ 's beliefs are contradictory.

A similar reasoning underlies the derivation of ignorance implicatures. Assuming that (1) has among its alternatives each of its disjuncts (a.o., Sauerland 2004; Katzir 2007), the hearer will conclude from MQ that (i) it's not true that the speaker believes

\footnotetext{
7 The formulation of (12) is adapted from Fox (2007). As Fox discusses, a crucial property of (12) is its reliance on alternatives to a sentence, which in turn requires a theory of alternatives. We leave this issue aside as it is tangential to our present purposes. For discussion on theories of alternatives see Katzir (2007), Breheny et al. (2017) and references therein.
} 
that Olivia took Logic and that (ii) it's not true that the speaker believes that Olivia took Algebra. Together, these two inferences give rise to the IGNORANCE implicature in (1-b): the speaker knows that one of the two disjuncts is true, but she doesn't know which one is. Crucially, note that OS cannot apply in this case since strengthening further those inferences would otherwise lead to the conclusion that the speaker has contradictory beliefs, namely that the speaker believes (1) to be true but both of (1)'s disjuncts to be false.

In sum, the Neo-Gricean approach provides a unified analysis of the EXCLUSIVITY and IGNORANCE implicatures arising from disjunctions based on the interaction between MQ and the OS assumption. We turn now to a second and very different conception of implicatures coming from the Grammatical approach.

This second conception has its origins in early criticism of the Gricean notion of implicatures (e.g., Cohen 1971) and envisions these inferences more on the semantic side of the semantics-pragmatics interface. That is, on this approach, scalar implicatures arise from the compositional calculation of meaning (a.o., Chierchia 2004, 2013; Chierchia et al. 2012; Magri 2009; Romoli 2012; Meyer 2013; Fox 2007; Bar-Lev and Fox 2020; Marty 2017). A common implementation of this approach makes use of a covert exhaustivity operator in the syntax, generally referred to as 'EXH', the application of which directly gives rise in (1) to the EXCLUSIVITY implicature in (1-a). For our initial purposes, EXH can be defined as in (15-a), where $\phi$ is any sentence and $\operatorname{ALT}(\phi)$ the set of alternatives to $\phi$. In a nutshell, applying EXH to a sentence $\phi$ outputs $\phi$ and the negation of all of $\phi$ 's alternatives that are 'innocently excludable', (15-b), i.e., those alternatives to $\phi$ that can be consistently negated together without contradicting $\phi$ or entailing the truth of other alternatives. Note that the definition of innocent exclusion in (15-b) is parallel to, and effectively doing the work of MQ plus the OS assumption, including the non-contradiction clause.

$$
\begin{aligned}
& \text { a. Exhaustivity operator (EXH) } \\
& \llbracket \operatorname{EXH} \phi \rrbracket(w)=\llbracket \phi \rrbracket(w) \wedge \forall \psi \in \mathrm{IE}(\phi, \operatorname{ALT}(\phi))[\neg \llbracket \psi \rrbracket(w)]
\end{aligned}
$$

\section{b. Innocently Excludable alternatives (IE)}

$$
\mathrm{IE}(\phi, C)=\bigcap\left\{\begin{array}{l|l}
C^{\prime} & \begin{array}{l}
C^{\prime} \subseteq C \text { and } C^{\prime} \text { is a maximal subset of } C \\
\text { such that }\left\{\neg \psi: \psi \in C^{\prime}\right\} \cup\{\phi\} \text { is consistent }
\end{array}
\end{array}\right\}
$$

Now, some versions of the grammatical approach maintains that, unlike the EXCLUSIVITY implicature in (1-a) (i.e., a secondary implicature in Neo-Gricean terms), IGNORANCE implicatures arise in the same way as before, through pragmatic reasoning based on MQ. On this view, the different implicatures observed in (1) are thus obtained as follows:

$$
\text { EXH [Olivia took Logic or Algebra] }
$$

$\mathrm{IE}$-alternatives $=\{$ Olivia took Logic and Algebra $\}$
a. By Exhaustification:
$\sim$ Olivia didn't take both Logic and Algebra
b. By MQ:
$\sim$ the speaker is ignorant about whether Olivia took Logic
$\sim$ the speaker is ignorant about whether Olivia took Algebra 
Following Meyer (2013) however, more recent versions of the grammatical approach have proposed that ignorance inferences are also derived in the grammar through the interaction of EXH with another another covert operator $K$ representing the speaker's beliefs (e.g., Meyer 2013; Buccola and Haida 2019). At the core of this proposal is the assumption — called the Matrix $K$ Axiom — that assertively used sentences contain the covert doxastic operator $K$, adjoined at the matrix level at LF (cf. Chierchia 2006; Alonso-Ovalle and Menéndez-Benito 2010). Much like the attitude verb believe, the Matrix $K$ operator universally quantifies over the speaker's doxastic alternatives, (17). The subscript $x$ refers to the doxastic source, i.e., the individual whose beliefs $K$ is quantifying over. In the cases that we will be concerned with, $x$ will always be the speaker, hence the notation $K_{s}{ }^{8}$

$$
\llbracket K_{x} \phi \rrbracket(w)=\forall w^{\prime} \in \operatorname{Dox}(x)(w)\left[\llbracket \phi \rrbracket\left(w^{\prime}\right)\right]
$$

Meyer shows that the Matrix $K$ Axiom, together with EXH, derives the ignorance inferences previously attributed to the working of MQ. In particular, assuming that (1) has the LF in (18) gives rise to the desired result: ${ }^{9,10}$

\section{$\left[\mathrm{EXH}_{(1)}\left[K_{S}\left[\mathrm{EXH}_{(2)}[\right.\right.\right.$ Olivia took Logic or Algebra $\left.\left.]\right]\right]$}

a. Exhaustification below $\mathrm{K}$

(i) $\mathrm{IE}=\{[\mathrm{L} \wedge \mathrm{A}]\}$

(ii) Implicature: $\neg[\mathrm{L} \wedge \mathrm{A}]$

b. Exhaustification above $\mathrm{K}$

(i) $\mathrm{IE}=\left\{\begin{array}{c}{\left[\mathrm{K}_{s} \mathrm{EXH}_{(2)} \mathrm{L}\right],\left[\mathrm{K}_{s} \mathrm{EXH}_{2} \mathrm{~A}\right],\left[\mathrm{K}_{s} \mathrm{EXH}_{(2)} \mathrm{L} \wedge \mathrm{A}\right] \text {, }} \\ {\left[\mathrm{K}_{s} \mathrm{~L}\right],\left[\mathrm{K}_{s} \mathrm{~A}\right],\left[\mathrm{K}_{s} \mathrm{~L} \wedge \mathrm{A}\right]}\end{array}\right\}$

(ii) Implicatures: $\neg \mathrm{K}_{s}[\mathrm{~L} \wedge \neg \mathrm{A}], \neg \mathrm{K}_{s}[\mathrm{~A} \wedge \neg \mathrm{L}], \neg \mathrm{K}_{s}[\mathrm{~L} \wedge \mathrm{A}], \neg \mathrm{K}_{s}[\mathrm{~L}]$, $\neg \mathrm{K}_{s}[\mathrm{~A}]$

c. Exhaustification outcome

$\left[\mathrm{EXH}_{(1)}\left[K_{s}\left[\mathrm{EXH}_{(2)}[\right.\right.\right.$ Olivia took Logic or Algebra]]]]

$=\mathrm{K}_{s}[\mathrm{~L} \vee \mathrm{A}] \wedge \mathrm{K}_{s} \neg[\mathrm{L} \wedge \mathrm{A}] \wedge \neg \mathrm{K}_{s}[\mathrm{~L}] \wedge \neg \mathrm{K}_{s}[\mathrm{~A}]$

$=\mathrm{K}_{s}[\mathrm{~L} \vee \mathrm{A}] \wedge \mathrm{K}_{s} \neg[\mathrm{L} \wedge \mathrm{A}] \wedge \mathrm{I}_{s}[\mathrm{~L}] \wedge \mathrm{I}_{s}[\mathrm{~A}]$

Exhaustification below $K$ gives rise to the EXCLUSIVITY implicature, by negating the conjunctive alternative to $\mathrm{EXH}_{(2)}$ 's prejacent. Exhaustification above $K$ gives rise to the IGNORANCE inferences: those inferences obtain by computing the implicatures associated with the alternatives to $\mathrm{EXH}_{(1)}$ 's prejacent corresponding roughly to its independent disjuncts, both with and without $\mathrm{EXH}_{(2)}$, all of which are innocently excludable. The resulting outcome, (18-c), delivers the expected pattern of inferences for simple dis-

\footnotetext{
${ }^{8}$ Here and throughout this paper, we will use $K$ in the meta-language to abbreviate the denotation of the Matrix K operator. That is, we adopt the following convention: $\llbracket K_{x} \phi \rrbracket$ if and only if $K_{x} \phi$.

9 For the sake of simplicity, we use $\mathrm{L} \wedge \mathrm{A}$ as short forms for the sentences Olivia took Logic and Olivia took Algebra, respectively. As is customary, we write $I_{S}(\phi)$ for 'the speaker $s$ is ignorant about $\phi$ ', where $I_{S}(\phi)$ holds if and only if both $\neg K_{S}(\phi)$ and $\neg K_{S}(\neg \phi)$ hold.

10 Following Meyer (2013), we assume that the matrix K operator is immune from deletion: if a sentence includes $K$ then it is preserved in the structural alternatives to that sentence. We do not assume however that this immunity applies to the occurrences of EXH, which can be deleted as usual by substitution with a subconstituent (for a different view, see Meyer 2013).
} 
junctive sentences like (1): the speaker believes that Olivia took Logic or Algebra but not both, and the speaker is ignorant about whether she took Logic and about whether she took Algebra.

This concludes our overview of the two approaches. While we did not go through a variety of details and subtleties, it is enough as a background for us to grasp the challenge raised by FREE CHOICE, to which we now turn.

\subsection{The challenge of free choice}

Consider again the free choice inference in (2):

Olivia can take Logic or Algebra.

$\sim$ Olivia can choose between the two classes

FREE CHOICE

As is well known, free choice is puzzling from the perspective of traditional approaches to the meaning of modals and disjunction: the predicted meaning of (2) only entails that Olivia can take Logic or she can take Algebra. To complicate things further, free choice disappears under negation. That is, the negative counterpart of (2) in (19) doesn't merely convey that it's not true that Olivia doesn't have free choice, but rather that Olivia can't take either of the two classes. The negated meaning of (2) in (19) is sometimes called 'double prohibition', a terminology which we will adopt here.

(19) Olivia cannot take Logic or Algebra.

$\sim$ Olivia cannot take either one

DOUBLE PROHIBITION

In essence, the challenge is to account for free choice in positive environments like (2) and, at the same time, for double prohibition in negative ones like (19). A prominent line of explanation takes the free choice-double prohibition alternation to teach us that we should treat free choice as implicatures, hence accounting immediately for their sensitivity to monotonicity. Additional support for this proposal comes from the observation that free choice inferences exhibit another characteristic feature of implicatures: they can be suspended or cancelled, as illustrated in (20).

(20) Olivia can take Logic or Algebra, but I don't remember which (one). t Olivia can choose between the two

Despite these striking similarities, we note that the implicature approach to free choice is by no means uncontroversial (we discuss some alternative accounts in Sect. 6). For now, what is important for us is that, if one assumes an implicature approach to free choice, there are important consequences for the debate between the pragmatic and grammatical approaches to implicatures. In particular, Fox (2007) has shown that deriving free choice is problematic under the former, but not under the latter. The gist of the challenge for the pragmatic approach is as follows. By the same Quantity-based reasoning as the one we described above, a sentence like (2) is to be compared by the hearer to its modalised alternatives corresponding to its independent disjuncts, (21-a) and (21-b) respectively. 

a. Olivia can take Logic.
b. Olivia can take Algebra.

Since these alternatives are both more informative than (2), the hearer shall conclude by MQ that it's not true that the speaker believes either. In other words, the hearer shall conclude that the speaker is ignorant about whether Olivia can take Logic and about whether Olivia can take Algebra. While this outcome can account for suspension cases like (20), it does not account however for genuine cases of free choice like (2), and it is unclear how to proceed from that point. In particular, it is worth noting that the OS assumption cannot apply in this case as it would otherwise lead to a contradiction with the asserted meaning. ${ }^{11}$ In sum, the pragmatic approach can only derive ignorance inferences about the disjuncts, whether the asserted disjunction is modalised as in (2) or a simple one as in (1). Therefore, if free choice inferences are scalar implicatures, deriving those implicatures is a challenge for this pragmatic approach. ${ }^{12}$

\subsection{The grammatical approach to free choice}

In contrast to the pragmatic approach, the grammatical approach has an easier time accounting for FREE CHOICE. For concreteness, we sketch here a version of this approach based on Bar-Lev and Fox (2020) (see also Bar-Lev 2018) but, as far as we can see, any version of this approach would be compatible with the following (see, among others, Fox 2007; Klinedinst 2007; Chemla 2010; Santorio and Romoli 2017).

As a starting point, the literal meaning of a sentence like (2) can be represented as shown in (22-a), where the symbol ' $\diamond$ ' is used to represent modal operators of possibility (the possibility modal 'can' in the present case). On this representation, (2) is true if and only if Olivia can take at least one of Logic and Algebra, as one would expect. While (22-a) does not account in itself for FREE CHOICE, note that its negation directly corresponds to double prohibition, (22-b).

$$
\begin{aligned}
& \text { a. } \diamond(\mathrm{L} \vee \mathrm{A}) \Leftrightarrow \diamond \mathrm{L} \vee \diamond \mathrm{A} \\
& \text { b. } \quad \neg \diamond(\mathrm{L} \vee \mathrm{A}) \Leftrightarrow \neg \diamond \mathrm{L} \wedge \neg \diamond \mathrm{A}
\end{aligned}
$$

LITERAL MEANING DOUBLE PROHIBITION

The approach by Bar-Lev and Fox (2020) accounts for the free choice-double prohibition pattern on the basis of two main ingredients. First, it assumes an extra layer to the exhaustification process: in addition to excluding a subset of alternatives to its prejacent, EXH also 'includes' a subset of other ones. To select which alternatives are thus includable, Bar-Lev and Fox (2020) propose a notion analogous to innocent exclusion, which they call 'innocent inclusion', defined as in (23-b) (alongside the notion of innocent exclusion in (23-a), repeated for convenience). In short, an alternative is

\footnotetext{
11 In addition, we note that any attempt to derive free choice for (2) by considering different alternatives for implicature computation (e.g., Kratzer and Shimoyama 2002) should make sure that it does not unwarrantedly extend to simple disjunctive sentences like (1), which cannot have the corresponding conjunctive meaning that Olivia took Logic and Algebra.

12 As mentioned in footnote 4, there are more recent proposals in the literature for deriving free choice as an implicature from a pragmatic perspective, which respond to Fox's (2007) challenge (a.o., Chemla 2010; Geurts 2010; Franke 2011). We cannot go into the details of these proposals here; see Romoli (2014) and Fox and Katzir (2019) for some critical discussion.
} 
innocently includable if it is in all maximally includable subsets of alternatives, which in turn are those alternatives which can be consistently included with the prejacent and the negation of all innocently excludable alternatives.

\section{a. Innocently Excludable alternatives (IE)}

$\mathrm{IE}(\phi, C)=\bigcap\left\{\begin{array}{l|l}C^{\prime} & \begin{array}{l}C^{\prime} \subseteq C \text { and } C^{\prime} \text { is a maximal subset of } C \text { s.t. } \\ \left\{\neg \psi: \psi \in C^{\prime}\right\} \cup\{\phi\} \text { is consistent }\end{array}\end{array}\right\}$

b. Innocently Includable alternatives (II)

$$
\mathrm{I}(\phi, C)=\bigcap\left\{\begin{array}{l|l}
C^{\prime \prime} & \begin{array}{l}
C^{\prime \prime} \subseteq C \text { and } C^{\prime \prime} \text { is a maximal subset of } C \text { s.t. } \\
\left\{\chi: \chi \in C^{\prime \prime}\right\} \cup\{\phi\} \cup\{\neg \psi: \psi \in \operatorname{IE}(\phi, C)\} \\
\text { is consistent }
\end{array}
\end{array}\right\}
$$

On this approach, the working of EXH is thus twofold: it excludes all innocently excludable alternatives while including all innocently includable ones, (24). For clarity, we notate Bar-Lev and Fox's exhaustivity operator as EXH ${ }^{I E+I I}$.

$$
\begin{aligned}
& \text { Exhaustivity operator for IE and II alternatives }\left(\mathbf{E X H}^{I E+I I}\right) \\
& \llbracket \operatorname{EXH}^{I E+I I} \phi \rrbracket(w)= \\
& \llbracket \phi \rrbracket(w) \wedge \forall \psi \in \operatorname{IE}(\phi, \operatorname{ALT}(\phi))[\neg \llbracket \psi \rrbracket(w)] \wedge \forall \chi \in \|(\phi, \operatorname{ALT}(\phi))[\llbracket \chi \rrbracket(w)]
\end{aligned}
$$

To illustrate how this operator works, consider again (2) and assume that this sentence is parsed as in (25). The formal alternatives to EXH's prejacent are those illustrated in (26).

$$
\mathrm{EXH}^{I E+I I} \text { [Olivia can take Logic or Algebra] }
$$

$$
\text { ALT }=\left\{\begin{array}{lr}
\text { Olivia can take Logic or Algebra } & \diamond(L \vee A) \\
\text { Olivia can take Logic } & \diamond \mathrm{L} \\
\text { Olivia can take Algebra } & \diamond \mathrm{A} \\
\text { Olivia can take Logic and Algebra } \diamond(\mathrm{L} \wedge \mathrm{A})
\end{array}\right\}
$$

Only one of these alternatives is in all maximally excludable subsets, $\diamond(L \wedge A)$. Hence, if it is relevant, this alternative can be innocently excluded. ${ }^{13}$ Crucially, the other three alternatives — namely, $\diamond(\mathrm{L} \vee \mathrm{A}), \diamond \mathrm{L}$ and $\diamond \mathrm{A}$ - are all innocently includable. Including those alternatives upon exhaustification of (2)'s meaning delivers the FREE CHOICE reading we were interested in, as illustrated in (27).

$$
\begin{aligned}
& \llbracket \mathrm{EXH}^{I E+I I}[\text { Olivia can take Logic or Algebra }] \rrbracket=\diamond(\mathrm{L} \vee \mathrm{A}) \wedge \neg \diamond(\mathrm{L} \wedge \mathrm{A}) \wedge \\
& \diamond \mathrm{L} \wedge \diamond \mathrm{A}
\end{aligned}
$$

The second ingredient, which is relevant for negative cases like (19), is a restriction on EXH's distribution that prevents it from appearing in the scope of negation in order to avoid meaning weakening. This restriction is usually formulated as an economy constraint along the lines of (28) (adapted from Fox and Spector 2018; see also Chier-

\footnotetext{
13 As Bar-Lev and Fox (2020) discuss, this alternative can also be pruned from the set of alternatives if not relevant. This, in turn, can account for the fact that the inference corresponding to the negation of the conjunctive alternative (i.e., Olivia cannot take both Logic and Algebra) is not always associated with sentences like (2), regardless of whether they give rise to FREE CHOICE.
} 
chia et al. 2012; Gajewski and Sharvit 2012; Spector and Sudo 2017; Enguehard and Chemla 2021 for similar proposals).

\section{Economy Constraint}

An occurrence of EXH in a sentence $S$ is not licensed if the resulting meaning of $\mathrm{S}$ with that occurrence of EXH is Strawson-entailed by $\mathrm{S}$ without it.

The application of (28) in cases like (19) preserves the good result in (22-b), namely double prohibition, by blocking the (unlicensed) exhaustification process shown in (29), the outcome of which would be logically weaker than the literal meaning of the base sentence.

$$
\neg(\operatorname{EXH}(\diamond(\mathrm{L} \vee \mathrm{A}))) \Leftrightarrow \neg \diamond \mathrm{L} \vee \neg \diamond \mathrm{A}
$$

Hence, the grammatical approach to implicatures can account for FREE CHOICE in a relatively straightforward way and, to the extent that we treat FREE CHOICE as an implicature, this result constitutes an argument for such an approach. In the following section, we move on to discuss the phenomenon of presupposition-based scalar implicatures.

\section{Presupposed scalar implicatures}

\subsection{The phenomenon}

Building on previous observations by Simons (2001b) and Russell (2006), Gajewski and Sharvit (2012) discuss sentences like (3) and (5), repeated from above, where a weak scalar item (e.g., some, or) is embedded under the scope of a negative factive predicate (e.g., unaware). Gajewski and Sharvit observe that such sentences have a salient reading on which their assertion in (a) retains its literal meaning, while their presupposition in (b) gives rise to a scalar implicature, (c).

(3) Noah is unaware that some of the students took Logic.

a. ASSERTION

Noah doesn't believe that any students took Logic

b. PRESUPPOSITION

Some of the students took Logic

c. PRESUPPOSED IMPLICATURE

$\sim$ Not all of the students took Logic

(5) Noah is unaware that Olivia took Logic or Algebra.

a. ASSERTION

Noah doesn't believe that Olivia took either one

b. PRESUPPOSITION

Olivia too Logic or Algebra

c. PRESUPPOSED IMPLICATURE

$\sim$ Olivia didn't take both Logic and Algebra 
Crucially, Gajewski and Sharvit show that these readings are distinct from the readings that would obtain if the target implicatures were computed at the level of the embedded clause, i.e., under the scope of unaware. To illustrate this point, consider the EXH-based approach to scalar implicatures that we have sketched so far, setting innocent inclusion aside. Applying EXH at the embedded level in (5) would deliver the reading in (30):

Noah is unaware that EXH [Olivia took Logic or Algebra]

$\mathrm{IE}=\{$ Olivia took Logic and Algebra $\}$

a. ASSERTION

Noah doesn't believe the following: Olivia took Logic or Algebra and not both Logic and Algebra

b. PRESUPPOSITION

Olivia took Logic or Algebra but not both Logic and Algebra

On this reading, (5) has the EXCLUSIVITY implicature we are looking for in its presupposition. The problem, however, is that this implicature is also present in the assertion, leading to an unwarranted weakening of the asserted content of (5). In particular, on this reading, (5) should be true if the speaker takes for granted that Olivia took either Logic or Algebra, and Noah believes that Olivia took both classes. This reading is weaker than the one we are after, and it is definitely a marked reading of (5), if possible at all. ${ }^{14}$ Similar observations extend to the example in (3). Deriving the observed readings of (3) and (5) is thus challenging for theories of scalar implicatures and presuppositions, and simply embedding an implicature operator in the scope of the factive predicate is not a solution. In the following, we turn to what is possibly the simplest way of addressing this challenge, namely to allow scalar implicatures to be computed separately in the assertion and in the presupposition.

\subsection{A unified grammatical approach and its problems}

In order to account for the puzzling readings above, Gajewski and Sharvit (2012) propose that scalar implicatures are computed in the assertion and in the presupposition of a sentence in a similar way but separately (see also Magri 2009 for a similar proposal). This proposal relies on the following two key components. First, it assumes a two-dimensional theory of meaning in the style of Karttunen and Peters (1979) on which a sentence $\phi$ denotes two propositions, its presupposition $\llbracket \phi \rrbracket^{p r s}$ and its assertion $\llbracket \phi \rrbracket^{a s r}$, that is $\llbracket \phi \rrbracket=\left\langle\llbracket \phi \rrbracket^{p r s}, \llbracket \phi \rrbracket^{a s r}\right\rangle$ (see also Mandelkern 2016 for a more recent bi-dimensional account). On this view, a sentence like (5) denotes for instance the following two propositions:

\section{a. «Noah is unaware that Olivia took Logic or Algebra $\rrbracket^{\text {prs }}$ $=\lambda w$. Olivia took Logic or Algebra in $w$}

\footnotetext{
14 Native speakers we have consulted consistently judged (5) as false in such cases. The unavailability of this reading is not surprising however. It directly relates to the general observation that scalar implicatures tend to not arise at the assertion level in downward-entailing environments (e.g., under negation and other scale-reversal contexts). This is in fact the core motivation for the Economy Constraint introduced in (28), which predicts the putative parse of (5) in (30) to not be licensed.
} 


\section{b. $\llbracket$ Noah is unaware that Olivia took Logic or Algebra $\rrbracket^{\text {asr }}$ $=\lambda w$. Noah doesn't believe in $w$ that Olivia took Logic or Algebra}

Second, when the meaning of a sentence is exhaustified, exhaustification is performed at both dimensions separately. For exposition reasons, we will follow the implementation of this idea offered in Magri (2009) and rendered in (32). This implementation directly builds upon the basic conceptualisation of EXH introduced in (15) and, in particular, upon the notion of innocent exclusion defined in (15-b). In a nutshell, when EXH is applied to a sentence meaning, it applies separately to its assertion and to its presupposition. ${ }^{15}$

$$
\begin{array}{ll}
\text { a. } & \llbracket \operatorname{EXH} \phi \rrbracket(w)=\left\langle\llbracket \operatorname{EXH} \phi \rrbracket^{p r s}(w), \llbracket \operatorname{EXH} \phi \rrbracket^{a s r}(w)\right\rangle \\
\text { b. } & \llbracket \operatorname{EXH} \phi \rrbracket^{p r s}(w)=\llbracket \phi \rrbracket^{p r s}(w) \wedge \forall \psi \in \operatorname{IE}\left(\phi, \operatorname{ALT}^{p r s}(\phi)\right)\left[\neg \llbracket \psi \rrbracket^{p r s}(w)\right] \\
\text { c. } & \llbracket \operatorname{EXH} \phi \rrbracket^{a s r}(w)=\llbracket \phi \rrbracket^{a s r}(w) \wedge \forall \psi \in \operatorname{IE}\left(\phi, \operatorname{ALT}^{a s r}(\phi)\right)\left[\neg \llbracket \psi \rrbracket^{a s r}(w)\right]
\end{array}
$$

At the assertion level, EXH operates the same way as before. Thus for instance, for the some-sentence in (33), it gives us the familiar not-all implicature and, for a simple disjunctive case like (34), the familiar EXCLUSIVITY implicature.

\section{EXH $\left[{ }_{\phi}\right.$ Some of the students took Logic $]$}
a. $\llbracket \phi \rrbracket^{a s r}(w)=1$ iff some of the students took Logic in $w$
b. $\operatorname{IE}\left(\phi, \operatorname{ALT}^{a s r}(\phi)\right)=\{$ all of the students took Logic $\}$
c. $\llbracket \operatorname{EXH} \phi \rrbracket^{a s r}(w)=1$ iff some but not all of the students took Logic in $w$

EXH $\left[{ }_{\phi}\right.$ Olivia took Logic or Algebra $]$

a. $\llbracket \phi \rrbracket^{a s r}(w)=1$ iff Noah took Logic or Algebra in $w$

b. $\operatorname{IE}\left(\phi, \operatorname{ALT}^{a s r}(\phi)\right)=\{$ Olivia took Logic and Algebra $\}$

c. $\llbracket \operatorname{EXH} \phi \rrbracket^{a s r}(w)=1$ iff Noah took Logic or Algebra but not both in $w$

In addition, the strengthening operation now applies also at the presuppositional level: the exhaustified presupposition of a sentence $\phi$ corresponds to the conjunction of $\phi$ 's presupposition together with the negation of the presuppositions of all of $\phi$ 's alternatives which are innocently excludable in the presuppositional dimension. This theoretical move offers a simple solution to the kind of challenge raised by sentences like (3) and (5): applying EXH at the matrix level of these sentences now delivers the readings we were after, as illustrated in (35) and (36) respectively. ${ }^{16}$

EXH $\left[{ }_{\phi}\right.$ Noah is unaware that some of the students took Logic]

a. ASSERTION

$\operatorname{IE}\left(\phi, \operatorname{ALT}^{a s r}(\phi)\right)=\{\}$

$\llbracket \operatorname{EXH} \phi \rrbracket^{a s r}(w)=1$ iff N. doesn't believe in $w$ that any students took Logic

\footnotetext{
15 Gajewski and Sharvit (2012) use a slightly different, yet comparable meaning strengthening mechanism, the composition rule of STRONG APPLICATION postulated in Chierchia (2004). The differences between EXH and STRONG APPLICATION are orthogonal to our present purposes.

16 This proposal also derives as genuine scalar implicatures the stronger form of the so-called implicated presuppositions (Sauerland 2008). As it is not relevant to our purposes here, we set this aspect aside; see Magri (2009) and Marty (2017, 2019) for discussion.
} 


\section{b. PRESUPPOSITION}

$\operatorname{IE}\left(\phi, \operatorname{ALT}^{p r s}(\phi)\right)=\{\mathrm{N}$. is unaware that all of the students took Logic $\}$

$\llbracket \operatorname{EXH} \phi \rrbracket^{p r s}(w)=1$ iff some but not all of the students took Logic in $w$

EXH $\left[{ }_{\phi}\right.$ Noah is unaware that Olivia took Logic or Algebra]

a. ASSERTION

$\operatorname{IE}\left(\phi, \operatorname{ALT}^{a s r}(\phi)\right)=\{\}$

$\llbracket \operatorname{EXH} \phi \rrbracket^{a s r}(w)=1$ iff N. doesn't believe in $w$ that O. took either one

b. PRESUPPOSITION

$\operatorname{IE}\left(\phi, \operatorname{ALT}^{p r s}(\phi)\right)=\{\mathrm{N}$. is unaware that O. took Logic and Algebra $\}$

$\llbracket \operatorname{EXH} \phi \rrbracket^{p r s}(w)=1$ iff O. took Logic or Algebra, but not both in $w$

Thus for instance, on the parse in (36), the sentence in (5) presupposes that Olivia took Logic or Algebra together with the EXCLUSIVITY implicature that she didn't take both. Crucially, this implicature is only computed at the presupposition level. At the assertion level, EXH leaves the meaning of (5) unaffected because there isn't any innocently excludable alternatives to the assertion. In other words, EXH is effective at the presupposition level, but vacuous at the assertion level. This outcome gives us the desired reading of (5). Similar observations hold for (3) on the parse in (35).

While these results are promising, Spector and Sudo (2017) raise two important challenges for this unified approach to implicatures and presupposed implicatures. First, they observe that, in contrast to (3) and (5), their positive counterparts can be felicitously uttered in a context in which the stronger presuppositions of their target alternatives are common knowledge. The contrast in (37) illustrates this observation using the scalar item some.

CONTEXT: The interlocutors know that all of the students took Logic; Noah, however, has no idea that Logic is very popular among the students.

a. Noah is aware that SOME of the students took Logic.

b. \#Noah is unaware that SOME of the students Logic.

As Spector and Sudo discuss, this contrast shows that, unlike the presupposition of (37-b), the one of (37-a) does not give rise to a not-all implicature in the suggested context for otherwise (37-a) would also be perceived as infelicitous. This difference between (37-b) and its positive counterpart (37-a) raises a direct issue for the unified approach by Gajewski and Sharvit (2012): since both these sentences have the same presuppositions (i.e., some of the students took Logic) and the same presuppositional competitors (i.e., those derived by replacing some with all in the embedded clause), both sentences are predicted on this approach to be strengthened in a parallel fashion and thus to be infelicitous in the same contexts, contrary to facts.

Second, Spector and Sudo (2017) point out another data point that is left unexplained by the unified approach: an utterance of (5) is infelicitous in a context in which one of the embedded disjuncts is already common knowledge, as illustrated in (38) (modelled after example (53) in Spector and Sudo 2017). This observation is puzzling since the presupposition of (38) is satisfied in such contexts, and this regardless of the absence or presence of an EXCLUSIVITY implicature. 
(38) CONTEXT: The interlocutors know that Olivia only took Logic.

\#Noah is unaware that Olivia took Logic or Algebra.

Hence, the grammatical approach to presupposed implicatures developed in Gajewski and Sharvit (2012) and Magri (2009) derives the desired readings of (3) and (5), but it also faces the new challenges identified by Spector and Sudo (2017). In the remainder of this section, we sketch the alternative proposal by Spector and Sudo (2017) to take up both these challenges.

\subsection{A hybrid account}

In contrast to the previous approach, Spector and Sudo (2017) argue that there should be two distinct forms of scalar strengthening, one operating at the assertion level and the other at the presupposition level. At the assertion level, Spector and Sudo assume that scalar strengthening is performed by application of the exhaustivity operator. Crucially, however, they propose to refine the semantics of EXH so as to capture its interaction with presuppositions. Specifically, adopting a trivalent semantics for presuppositions, they propose to adjust the bivalent definition of EXH in (15) to a trivalent setting so as to let EXH pass up the presuppositions of the alternatives it excludes, just like negation passes up the presuppositions of the sentence it negates. ${ }^{17}$ On this refinement, the meaning of a sentence like (37-a) can be strengthened as shown below. In a nutshell, if the all-alternative to (37-a) is negated by the working of EXH, this negated alternative will then pass up its (stronger) presupposition to the whole sentence, which will thus presuppose that all the students took Logic.

(37-a) EXH [Noah is aware that some of the students took Logic]

$\mathrm{IE}=\{$ Noah is aware that all of the students took Logic $\}$

a. ASSERTION

Noah believes that some of the students took Logic, but he doesn't believe that all of them did

b. PRESUPPOSITION

Some of the students took Logic, and all of them did

\footnotetext{
17 We refer the reader to Spector and Sudo (2017) for the relevant definitions (see in particular their Section 5.1, (25), (26) and (27)). In short, Spector and Sudo's adjustments are twofold. First, the definition of EXH in (15-a) is adapted to a trivalent setting as in (i) so as to allow EXH to behave as a 'presupposition hole' with respect to the presupposition of the alternatives: «EXH $\phi(w) \rrbracket$ is undefined if any of $\phi$ 's alternatives is undefined. Second, the notion of IE-alternatives in (15-b) is redefined by making use of strong negation: the negation of an alternative $\psi$ with presupposition $p$ is true if and only if $p$ is true and $\psi$ is false.
}

(i) Definition of EXH from Spector and Sudo (2017: (63))

$\llbracket \operatorname{EXH} \phi \rrbracket(w)$

$=\left\{\begin{array}{cccl}\# & \text { iff } & \llbracket \phi \rrbracket(w)=\# & \text { or for some } \psi \in \operatorname{IE}(\phi, \operatorname{ALT}(\phi)), \llbracket \psi \rrbracket(w)=\# \\ 1 & \text { iff } & \llbracket \phi \rrbracket(w)=1 & \text { and for all } \psi \in \operatorname{IE}(\phi, \operatorname{ALT}(\phi)), \llbracket \psi \rrbracket(w)=0 \\ 0 & \text { iff } & \llbracket \phi \rrbracket(w)=0 & \text { or for some } \psi \in \operatorname{IE}(\phi, \operatorname{ALT} \phi)), \llbracket \psi \rrbracket(w)=1 \\ & & & \text { and for no } \psi \in \operatorname{IE}(\phi, \operatorname{ALT}(\phi)), \llbracket \psi \rrbracket(w)=\#\end{array}\right\}$ 
At the presupposition level, on the other hand, Spector and Sudo propose that strengthening follows from an independent pragmatic principle along the lines of Maximize Presupposition!, which they call Presupposed Ignorance Principle (henceforth, PIP). The PIP makes a sentence infelicitous if that sentence has an alternative with a logically stronger presupposition that is satisfied in context, (39). ${ }^{18}$

(39) Presupposed Ignorance Principle (Spector and Sudo 2017, (5)/(56))

Let $p$ be the presupposition of sentence $\phi$. If $\phi$ has an alternative $\psi$ presupposing $q$ and $q$ asymmetrically entails $p, \phi$ is infelicitous in context $c$ if $q$ is satisfied in $c$, i.e., if $q$ is Common Knowledge in the context, $\operatorname{CK}(q)$.

The PIP can straightforwardly account for the infelicity of examples like (38), which was left unexplained by the previous approach. In a nutshell, (38) competes with the alternative Noah is unaware that Olivia took Logic, the presupposition of which is logically stronger than that of (38) and is satisfied in the given context since CK(Olivia took Logic). By application of the PIP, (38) is predicted to trigger the ignorance inference $\neg \mathrm{CK}($ Olivia took Logic) which contradicts common knowledge in that context, accounting thus for the infelicity of (38).

Next, the interactions between both scalar strengthening mechanisms provides an account of the asymmetry observed in (37). As we saw, in positive cases like (37-a), exhaustification has two related effects: EXH strengthens the meaning of its prejacent by negating the assertion of the all-alternative and subsequently by passing up the (stronger) presupposition of that alternative. Following this strengthening, the working of the PIP becomes vacuous, for the resulting presupposition is already maximally strong, accounting thus for the felicity of (37-a) in the suggested context. In negative cases like (37-b), however, it goes the other way around: the working of EXH is now vacuous since the corresponding all-alternative is not excludable, and so the PIP effectively applies, giving rise to the presupposed ignorance inference $\neg \mathrm{CK}$ (all of the students took Logic). In a context where it is common knowledge that all of the students took Logic, the generation of this inference leads to a contextual contradiction, exactly as in (38), accounting for the infelicity of (37-b) in such contexts.

(37-b) EXH [Noah is unaware that some of the students took Logic]

$\mathrm{IE}=\{\}$

a. ASSERTION

Noah doesn't believe that some of the students took Logic

b. PRESUPPOSITION

Some of the students took Logic

c. PRESUPPOSED IGNORANCE:

$\leadsto \neg$ CK[all of the students took Logic]

by the PIP

To summarise, Spector and Sudo (2017) propose a hybrid approach to scalar implicatures. This approach relies on a grammatical theory of implicatures at the assertion

\footnotetext{
18 Note that, in contrast to Maximize Presupposition!, the PIP leaves out the requirement that the presuppositional competitors to a given sentence be contextually equivalent to that sentence, allowing in effect more competitors than Maximize Presupposition!. See Spector and Sudo (2017), Anvari (2018) and Marty and Romoli (2020) for discussion.
} 
level, but on a pragmatic one at the presupposition level. Crucially, the two scalar strengthening mechanisms operate at one particular level and in a determined order: (i) at the assertion level, EXH negates the assertion of certain alternatives and passes up their presuppositions, and (ii) at the presupposition level, the PIP derives weaker inferences about what is common knowledge on the basis of the outcome of (i). The resulting proposal accounts for the asymmetry between (37-a) vs. (37-b) and for additional infelicity effects like (38). We turn now to present the challenges that presupposed free choice raises for their view and examine presupposed ignorance in more detail.

\section{New challenges}

\subsection{Presupposed free choice}

With these ingredients in place, we can now go back to sentences like (6) and explain the challenges they raise for Spector and Sudo's (2017) hybrid account.

(6) Noah is unaware that Olivia can take Logic or Algebra.

a. ASSERTION

Noah doesn't believe that Olivia can take either one

b. PRESUPPOSITION

Olivia can take Logic or Algebra

c. PRESUPPOSED FREE CHOICE

$\sim$ Olivia can take Logic and she can take Algebra

As we already mentioned, (6) has a salient reading suggesting that Olivia can take Logic and that she can take Algebra, while conveying that it's not true that Noah believes she can take either one. That is, in a way similar to the implicatures in (3) and (5), we observe that the free choice inference appears here in the presupposition but not in the assertion. As we have seen in Sect. 3.1, this observation already tells us that FREE CHOICE cannot simply be derived at the level of the embedded clause in a regular way (or it would show up both in the presupposition and in the assertion). Cases similar to (6) can be easily reproduced with other factive verbs and adjectives, as illustrated in (40) and (41). ${ }^{19}$

\footnotetext{
19 Alxatib (2014) and Bar-Lev and Fox (2020) discuss similar data involving only like the sentence in (i), which also exhibits a presupposed free choice reading. As Alxatib (2014) shows, the free choice inference in (i-b) survives embeddings just like other presuppositions. Alxatib (2014) and Bar-Lev and Fox (2020) take these data to teach us something about the semantics of only and EXH. However, their accounts do not generalise to the other cases of presupposed free choice discussed in this paper. Conversely, the account we will later propose extends to data like (i).
}

(i) Olivia is only allowed to take Logic or Algebra
a. ASSERTION
Olivia is not allowed to take any other course
b. PRESUPPOSED FREE CHOICE
$\sim$ Olivia can take Logic and she can take Algebra 
(40) Noah didn't realise that Olivia can take Logic or Algebra.

a. ASSERTION

Noah doesn't believe that Olivia can take either class

b. PRESUPPOSITION

Olivia can take Logic or Algebra

c. PRESUPPOSED FREE CHOICE

$\sim$ Olivia can take Logic and she can take Algebra

(41) Noah is sorry that Olivia can take Logic or Algebra.

a. ASSERTION

Noah wants that Olivia cannot take either Logic or Algebra

b. PRESUPPOSITION

Olivia can take Logic or Algebra

c. PRESUPPOSED FREE CHOICE

$\sim$ Olivia can take Logic and she can take Algebra

These novel cases are challenging for the system proposed in Spector and Sudo (2017). To begin with, the application of the PIP predicts an utterance of (6) to be infelicitous if it is common knowledge that Olivia can take Logic and that she can take Algebra (i.e., that she has free choice between the two). This prediction obtains because (6) has the alternatives in (42), the presuppositions of which are logically stronger than the disjunctive presupposition of (6) and satisfied in the suggested context. This prediction is however incorrect: all the sentences above are intuitively felicitous in a context in which it is common knowledge that Olivia can choose between Logic and Algebra.

a. Noah is unaware that Olivia can take Logic. PRESUPPOSITION: Olivia can take Logic

b. Noah is unaware that Olivia can take Algebra. PRESUPPOSITION: Olivia can take Algebra

This issue would of course disappear if we could derive the free choice inference as a presupposition of (6), since, in that case, (6) would presuppose that Olivia can take Logic and that she can take Algebra, rendering then the working of the PIP vacuous. The problem however is that accounting for this inference in the system of Spector and Sudo (2017) is problematic. First, deriving this inference with the pragmatic side of their system is challenging for the same reasons as deriving regular FREE CHOICE is challenging for a pragmatic approach to assertion-based implicatures. Second, allowing this inference to arise from the working of EXH at the assertion level would undo their account of the asymmetry in (37).

To illustrate both points in turn, consider first what we can derive just by using the PIP. As exemplified below, in a run-of-the-mill context, a sentence like (6) gives rise by the PIP to the presupposed ignorance inferences that it is not common ground that Olivia can take Logic and that it is not common ground that she can take Algebra. These inferences, however, do not lead to presupposed free choice. 
(6) Noah is unaware that Olivia can take Logic or Algebra.

a. $\neg$ CK[Olivia can take Logic]

by the PIP

b. $\neg$ CK[Olivia can take Algebra]

by the PIP

This observation is in fact entirely parallel to the observation that the Maxim of Quantity cannot derive assertion-based free choice inferences in unembedded cases like (2). Rather, MQ can only derive the ignorance inferences that the speaker is not certain that Olivia can take Logic and not certain that Olivia can take Algebra.

(2) Olivia can take Logic or Algebra.

a. $\neg \mathrm{K}_{s}$ [Olivia can take Logic]

b. $\neg \mathrm{K}_{s}$ [Olivia can take Algebra]

Another option in Spector and Sudo's (2017) system would be to derive presupposed free choice as a presupposition arising through the exhaustification of the assertion. This option would indeed give us the reading with the stronger free choice presupposition and subsequently prevent the PIP from being effective. The problem, however, is that this cannot be achieved without losing Spector and Sudo's (2017) account of the asymmetry between (37-a) and (37-b). To see this, consider a minimal extension of Spector and Sudo's (2017) definition of EXH (see footnote 17) that leaves room for II-alternatives so that $\mathrm{EXH}^{I E+I I}$ negates all IE-alternatives and passes up their presuppositions and, in addition, EXH ${ }^{I E+I I}$ includes all II-alternatives and passes up their presuppositions. Going back to (6), let us see now what we can derive by applying this operator globally as in (43-a), which can be represented schematically as in (43-b) (where ' $\square$ ' represents the universal modal associated with Noah's doxastic alternatives and the presupposition is indicated as subscripted).

$$
\begin{aligned}
& \text { a. } \operatorname{EXH}^{I E+I I}[\text { Noah is unaware that Olivia can take Logic or Algebra }] \\
& \text { b. } \operatorname{EXH}^{I E+I I}[\neg \square[\diamond[\mathrm{L} \vee \mathrm{A}]]] \diamond[\mathrm{L} \vee \mathrm{A}]
\end{aligned}
$$

Consider now the set of formal alternatives in (44). ${ }^{20}$

$$
A L T=\left\{\begin{array}{ll}
\text { Noah is unaware that Olivia can take Logic or Algebra }[\neg \square[\diamond[L \vee A]]]_{\diamond[L \vee A]} \\
\text { Noah is unaware that Olivia can take Logic } & {[\neg \square[\diamond L]] \diamond L} \\
\text { Noah is unaware that Olivia can take Algebra } & {[\neg \square[\diamond A]] \diamond A}
\end{array}\right\}
$$

None of these formal alternatives are innocently excludable. To see this, it is enough to note that the exclusion of one disjunct would necessarily lead to the inclusion of the other. On the other hand, as in the simple unembedded case, the alternatives corresponding to the independent (modalised) disjuncts are both innocently includable. Therefore, the result of exhaustification would be as follows:

$$
\llbracket(43-\mathrm{a}) \rrbracket=[\neg \square[\diamond[\mathrm{L} \vee \mathrm{A}]]] \diamond[\mathrm{L} \vee \mathrm{A}] \wedge[\neg \square[\diamond \mathrm{L}]] \diamond \mathrm{L} \wedge[\neg \square[\diamond \mathrm{A}]] \diamond \mathrm{A}
$$

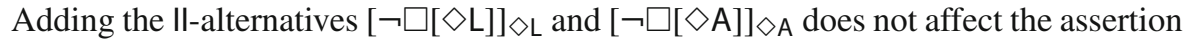
of (43-a). However, it adds to (43-a)'s plain presupposition two novel presuppositions,

\footnotetext{
${ }^{20}$ We leave the conjunctive alternative out for simplicity, but the end result does not change if we leave it in.
} 
namely $\diamond \mathrm{L}$ and $\diamond \mathrm{A}$. Hence, we derive for (43-a) the desired presupposed free choice reading that Olivia can take Logic $(\diamond \mathrm{L})$ and that she can take Algebra $(\diamond \mathrm{A})$.

These results are promising since they would allow us to address the challenge of presupposed free choice in Spector and Sudo's (2017) system. The problem however is that the very same reasoning and derivation can be reproduced with sentences like (3), hence losing the prediction that (3) should be infelicitous in a context in which it is common ground that all the students took Logic. To illustrate consider the parse of (3) in (46-a), together with its schematic representation in (46-b) and the formal alternatives in (46-c).

$$
\begin{aligned}
& \text { a. } \operatorname{EXH}^{I E+I I}[\text { Noah is unaware that some of the students took Logic }] \\
& \text { b. } \operatorname{EXH}^{I E+I I}[\neg \square[\exists]]_{\exists} \\
& \text { c. } \quad \text { ALT }:=\left\{\begin{array}{l}
\text { Noah is unaware that some students took Logic }[\neg \square[\exists]]_{\exists} \\
\text { Noah is unaware that all students took Logic }[\neg \square[\forall]]_{\forall}
\end{array}\right\}
\end{aligned}
$$

It is easy to verify that neither alternatives are innocently excludable. However, both of them are innocently includable and therefore the result of exhaustification should be as shown in (47). Here again, adding the II-alternative $[\neg \square[\forall]]_{\forall}$ does not add anything to the assertion, yet it strengthens the presupposition of (46-a) by adding the novel presupposition that all of the students took Logic $(\forall)$. This in turn incorrectly predicts that (3) should be felicitous in a context in which it is known that all of the students took Logic.

$$
\llbracket(46-\mathrm{a}) \rrbracket=[\neg \square[\exists]]_{\exists} \wedge[\neg \square[\forall]]_{\forall}
$$

Thus, if we allow a derivation along the lines of (43-a) to derive presupposed free choice, we lose the original result from Spector and Sudo (2017) about (46-a), and thus one of the main motivations underlying the elaboration of their system against a unified approach.

We note that there is in fact a principled way to block the unwarranted result in (47), one that we have in fact already discussed: if we assume that the distribution of EXH is regulated by the Economy Constraint in (28), then we expect its presence to not be licensed in this case since the resulting meaning with EXH is Strawsonentailed by the meaning of the base sentence without EXH. Such a constraint is in fact proposed and discussed in Spector and Sudo (2017) to deal with certain cases unrelated to our concerns. Yet it is critical to observe that appealing to (28) in the present cases would simply reverse the issue without solving it: this constraint would block representations like (46-a), hence preserving the good result from Spector and Sudo (2017), but it would also block representations like (43-a), leaving us then with no account of presupposed free choice.

For the sake of completeness, we note that, for the same reasons as before, deriving free choice by directly applying EXH ${ }^{I E+I I}$ to the embedded clause will not do:

$$
\text { Noah is unaware that } \mathrm{EXH}^{I E+I I} \text { [Olivia can take Logic or Algebra] }
$$

a. ASSERTION

Noah doesn't believe that Olivia can take Logic and can take Algebra 


\section{b. PRESUPPOSITION}

Olivia can take Logic and she can take Algebra

Putting aside that (48) would violate the Economy Constraint in (28), (48) simply does not give rise to the desired result: it has the free choice inference in its presupposition, but this inference is also present in the assertion under negation, which makes the asserted content too weak. Thus for instance, (48) is compatible with a situation in which, in all of Noah's belief worlds, Olivia can only take Logic. This might be a possible reading of this sentence, but it is certainly not the preferred one and not the one we are after. ${ }^{21}$ This point can be sharpened by looking at cases involving negative emotive factives like sorry, regret and dislike, as in (41). For instance, the reading of (41) we are after is one suggesting that Olivia can choose between both classes, while at the same time conveying that Noah doesn't want her to be allowed to take either one. As shown in (49), the reading we would obtain with embedded free choice would be once again too weak: (49) is compatible with Noah being okay with, or even wanting that, Olivia can take only one of the two classes, but not wanting that she can choose between the two. Similar observations hold for cases involving other factive verbs and adjectives.

Noah is sorry that EXH ${ }^{I E+I I}$ [Olivia can take Logic or can take Algebra]

a. ASSERTION

Noah wants that it's not true that Olivia can take Logic and can take Algebra

b. PRESUPPOSITION

Olivia can take Logic and can take Algebra

To summarise, presupposed free choice is challenging for the approach by Spector and Sudo (2017), which is otherwise successful in accounting for the interaction between presuppositions and scalar implicatures. As we discussed, presupposed free choice is a problem for Spector and Sudo (2017) in the same way assertive free choice is a problem for a pragmatic approach to assertion-based implicatures: in both cases, only ignorance is derived. Furthermore, deriving presupposed free choice as a side-effect of an exhaustification of the assertion leads to over-generation issues with related cases. These issues can be avoided by positing an economy condition on EXH's distribution such as (28), but we are then left with no account of presupposed free choice in Spector and Sudo's (2017) system. In the following, we move to another challenge coming from presupposed ignorance, which was the other central motivation for Spector and Sudo's (2017) proposal.

\footnotetext{
21 Although this reading is marked, it seems to us to be more accessible than the corresponding one with the embedded scalar implicature in simple disjunctive cases, as in (30) above. This might reflect a general difference between free choice and regular scalar implicatures in terms of embeddability under negation and downward entailing contexts (see Enguehard and Chemla 2021 for discussion).
} 


\subsection{Presupposed speaker-oriented ignorance}

As we have already seen, Spector and Sudo (2017) observe that a sentence like Noah is unaware that Olivia took Logic or Algebra cannot be felicitously uttered in a context in which it is common knowledge among the interlocutors that Olivia took Logic, or alternatively that Olivia took Algebra:

CONTEXT: The interlocutors know that Olivia only took Logic.

\#Noah is unaware that Olivia took Logic or Algebra.

As Spector and Sudo (2017) and Anvari (2018) discuss, this observation is not captured by the grammatical approach to presupposed implicatures that we presented in Sect. 3.2. The reason for that is that this approach is bound to the notion of innocent exclusion and therefore, in such disjunctive cases, it may only give rise to a presupposed EXCLUSIVITY implicature, i.e., the presupposed implicature that Olivia didn't take both Logic and Algebra. The presence of this implicature in (38) cannot account however for the infelicity of (38) since its contribution is contextually vacuous here (it is already taken for granted that Olivia didn't take both Logic and Algebra). The datapoint in (38) thus offers, at least prima facie, an empirical argument in favour of the pragmatic side of Spector and Sudo's (2017) system which, by contrast, can account for the infelicity of (38) through the PIP: an utterance of (38) is infelicitous in the suggested context because, by application of the PIP, it gives rise to two presupposed ignorance inferences, $\neg \mathrm{CK}($ Olivia took Logic) and $\neg \mathrm{CK}($ Olivia took Algebra $)$, one of which is contradictory with common knowledge.

We believe that Spector and Sudo's (2017) observation raises indeed an interesting challenge for a grammatical approach to presupposed implicatures. We also believe, however, that their description of the challenge surrounding presupposed ignorance is incomplete and that, in light of the broader empirical picture, postulating a principle like the PIP may not be a satisfying answer after all. Specifically, we make here the novel observation that similar infelicity effects reproduce in cases like (50) even if neither of the embedded disjuncts are common knowledge in the context.

a. \#Noah is unaware that I have two or more children.

b. \#Sue didn't realize that my wife is from France or Italy.

c. \#Mary was sorry that Sue had lunch with Noah or me yesterday.

We further observe that the infelicity effects found in these examples are in fact similar to those previously found in their non-embedded, non-presuppositional variants in (51) (a.o., Gazdar 1979; Fox 2007; Singh 2008, 2010; Fox and Katzir 2011).

a. \#I have two or more children.

b. \#My wife is from France or Italy.

c. \#Sue had lunch with Noah or me yesterday.

All these examples are odd presumably because they give rise to speaker-oriented ignorance inferences that stand in contradiction with common knowledge. Intuitively, a sentence like (50-a), just like its unembedded variant in (51-a), sounds odd because it conveys that the speaker is ignorant about how many children she actually has, and 
this piece of information arguably conflicts with the common assumption that people are normally knowledgeable about such personal facts. As Singh (2010) discusses, the generation of these ignorance inferences in simple disjunctive cases like (51) appears to be mandatory in normal conversational situations. This point is empirically supported for instance by the contrast in (52): while the exclusivity implicature associated with disjunctive sentences can be suspended, (52-a), overt attempts to cancel ignorance inferences tend to fail, (52-b).

\section{Jane speaks French or Italian.}

a. In fact, she speaks both languages.

b. \#In fact, she speaks French.

We note that the exact same observations hold of our presuppositional cases: while presupposed exclusivity can be suspended, (53-a), overt attempts to cancel presupposed ignorance inferences also tend to fail, (53-b).

Noah is unaware that Jane speaks French or Italian.

a. In fact, she speaks both languages.

b. \#In fact, she speaks French.

In the next section, we will argue that the parallels between all those cases call for a unified analysis and that a grammatical account of implicatures extending to ignorance inferences offers such a unification. For now, we observe that applying the PIP in cases like (50) cannot account by itself for the mandatory presence of those conflicting inferences. For instance, the PIP generates for a sentence like (50-a) the presupposed ignorance inference that the exact number of children that the speaker has is not common ground. This inference is unproblematic as long as this information is not mutually shared by the interlocutors (e.g., if this information is not known to the speaker's addressee). Consequently, the application of the PIP leaves the infelicity of the examples in (50) unaccounted for.

This issue would of course disappear if we could force in some way the outcome of the PIP to be narrowed down from common knowledge to the speaker's epistemic state, or alternatively if we could amend the PIP so as to generate primary implicatures targeting the speaker's epistemic state. In that case, a sentence like (50-a) would give rise to two speaker-oriented implicatures, $\neg \mathrm{K}_{s}$ (the speaker has two children) and $\neg \mathrm{K}_{s}$ (the speaker has more than two children), which together do conflict with common assumptions about the speaker's epistemic state. The problem, however, is that achieving these results in a pragmatic framework on the basis of the PIP is far from straightforward. We will illustrate this difficulty by discussing two ways to strengthen the results of the PIP which we take to be the most principled ones based on the previous literature. ${ }^{22}$

A first option would be to allow the outcome of the PIP to be strengthened by means of auxiliary pragmatic assumptions, for instance by appealing to the Authority

\footnotetext{
22 In the spirit of the grammatical approach, another option would be to integrate Meyer's (2013) Matrix K operator to Spector and Sudo's (2017) system so as to obtain a grammatical account of assertion-based ignorance implicatures. As Marty and Romoli (2020) discuss, however, this theoretical move alone cannot solve the issues raised by presupposed speaker-oriented ignorance.
} 
assumption originally proposed in Chemla (2008) for strengthening the outcome of Maximize Presupposition! (see Rouillard and Schwarz 2017, 2018 for discussion and refinements). Simplifying a bit, the idea would be that a PIP-generated inference of the form $\neg \mathrm{CK}(p)$, where $p$ is the presupposition of an alternative $\phi_{p}$ to the utterance, can be narrowed down to the speaker's epistemic state if the addressee assumes that the speaker could have convinced her that $p$ is true simply by presupposing $p$ (Authority assumption) and concludes then that the reason why the speaker didn't presuppose $p$ is because she didn't believe $p$ to be true in the first place, i.e., $\neg \mathrm{K}_{s}(p)$. As exemplified below, adding such assumptions to the working of the PIP would permit for instance to account for the fact that, in a run-of-the-mill context, a sentence like (54) can give rise to speaker-oriented ignorance inferences:

(54) Noah is unaware that Sue has two or more children.

a. By Quality:

$\leadsto \mathrm{K}_{s}$ (Sue has two or more children)

b. By application of the PIP:

$\sim \neg \mathrm{CK}($ Sue has two children $)$

$\leadsto \neg \mathrm{CK}($ Sue has more than two children $)$

c. From (54-b) by Authority assumptions:

$\leadsto \neg \mathrm{K}_{s}$ (Sue has two children)

$\sim \neg \mathrm{K}_{s}$ (Sue has more than two children)

d. Logical consequence from (54-a) and (54-c):

$\sim \mathrm{I}_{S}$ (Sue has two children $) \wedge \mathrm{I}_{S}($ Sue has more than two children $)$

Yet this reasoning does not easily extend to our problematic cases. The reason for that is that, on standard assumptions, a strengthening process like the one in (54) is to be thought of as an optional pragmatic enrichment. As such, the realization of this process should be guided by the plausibility of its outcome. In the cases at hand, this condition boils down to checking the consistency of the speaker's resulting beliefs. That is, the auxiliary assumptions used to derive (54-c) from (54-b) can be entertained only if they do not lead to the conclusion that the speaker's beliefs are contradictory. Consequently, for the cases we are primarily interested in such as (50-a), this line of analysis is a non-starter: if it is assumed that the speaker knows how many children she has, then any strengthening along the lines of (54-c) should be blocked and therefore (50-a) should be felicitous; alternatively, if such a strengthening is allowed, then the speakeroriented inferences so derived should not be conflicting and therefore (50-a) should be felicitous.

A second option, which would at least overcome the previous issue, would be to restate the PIP along the lines of MQ so as to directly generate speaker-oriented presupposed implicatures. For the sake of the argument, consider the following principle:

\section{Maxim of Presupposed Quantity (MPQ)}

Let $p$ be the presupposition of sentence $\phi_{p}$. If $\phi_{p}$ has an alternative $\psi_{q}$ presupposing $q$ and $q$ is more informative than $p$, then, if the speaker believes that both $p$ and $q$ are true, the speaker should prefer $\psi_{q}$ to $\phi_{p}$. 
Unlike the PIP, MPQ would generate in (50) the conflicting ignorance inferences we are after, accounting thus for the infelicity of these examples. Yet this result would come at the cost of spoiling the previous account of (38): in a context where it is common knowledge that Olivia only took Logic, the sentence Noah is unaware that Olivia took Logic or Algebra is presuppositionally equivalent and assertively more informative than its alternative Noah is unaware that Olivia took Logic. As a result, applying MPQ would simply be vacuous in (38) and therefore would leave the infelicity of this sentence unaccounted for. ${ }^{23}$

To summarize, Spector and Sudo's (2017) proposal only offers a partial answer to the challenge of presupposed ignorance: it accounts for the infelicity effects in (38) but leaves those in (50) unexplained. We have further discussed two natural extensions of their proposal and found them to fall short of an explanation at one point or another. While these results need not mean that the present data cannot receive a principled pragmatic explanation, they suggest that such an explanation would require certain assumptions that are non-standard in the pragmatic literature. ${ }^{24}$ Overall, the set of data we discussed suggests that the sort of implicature-generating mechanism we are after should have at least the following key features: (i) it should establish competition on the basis of logical strength, (ii) it should account for the mandatory presence of certain speaker-oriented ignorance inferences, and (iii) it should be modular enough to allow the generation of inferences that stand in contradiction with common knowledge. Finally, based on the novel parallels we unveiled, a fourth and last desideratum shall be added to this list: (iv) this mechanism should be general enough to apply to the assertion and presupposition of an utterance.

\subsection{Taking stock}

The data that we have gathered so far reveal a systematic parallelism between the assertion and presupposition levels in terms of EXCLUSIVITY, FREE CHOICE and IGNORANCE inferences. These parallels are illustrated and summarised in (9)-(11).

\footnotetext{
${ }^{23}$ MPQ also fails to account for the most basic instances of Maximize Presupposition! effects such as \#A sun is shining since the competitor, i.e., The sun is shining, is contextually equivalent to the actual utterance in normal contexts. This shortcoming is to be rooted into the fact that, just like MQ, MPQ establishes competition by considering informativeness rather than logical strength. Remedying this shortcoming is precisely what motivated Heim's (1991) postulation of Maximize Presupposition! in the first place.

${ }^{24}$ An anonymous reviewer noted for instance that there is an ad hoc modification of the Maxim of Presupposed Quantity in (55) that would permit one to derive the relevant ignorance inferences: (55) could be reformulated in reference to logical strength rather than informativeness, as in (i). We agree that the resulting principle is descriptively more adequate than the previous candidates. Note, however, that we are left with a rather unappealing pragmatic principle, one that is blind to contextual knowledge and only considers logical strength. The grammatical approach to presupposed implicatures that we will develop in the next section will be shown to have something along the lines of (i) as a more natural consequence.
}

(i) Presupposed Quantity with Contextual Blindness

Let $p$ be the presupposition of sentence $\phi_{p}$. If $\phi_{p}$ has an alternative $\psi_{q}$ presupposing $q$ and $q$ is logically stronger than $p$, then, if the speaker believes that both $p$ and $q$ are true, the speaker should prefer $\psi_{q}$ to $\phi_{p}$. 


\section{(9) Exclusivity and Presupposed Exclusivity}

a. Olivia took Logic or Algebra. $\sim$ Olivia didn't take both Logic and Algebra

b. Noah is unaware that Olivia took Logic or Algebra. $\sim$ Olivia didn't take both Logic and Algebra

(10) Free Choice and Presupposed Free Choice

a. Olivia can take Logic or Algebra. $\sim$ Olivia can take Logic and she can take Algebra

b. Noah is unaware that Olivia can take Logic or Algebra. $\sim$ Olivia can take Logic and she can take Algebra

\section{(11) Ignorance and Presupposed Ignorance}

a. Olivia took Logic or Algebra. $\sim$ The speaker doesn't know which of the two classes Olivia took

b. Noah is unaware that Olivia took Logic or Algebra. $\sim$ The speaker doesn't know which of the two classes Olivia took

We take these parallels to call for a unified analysis on which the assertion-based and presupposition-based versions of those three types of inferences are derived by the same meaning strengthening mechanism. Such an analysis should also account for the asymmetry between negative and positive sentences in (4) from Spector and Sudo (2017), repeated below for convenience.

(4) ConteXt: It is common knowledge that all of the students took Logic.

a. Noah is aware that SOME of the students took Logic.

b. \#Noah is unaware that SOME of the students Logic.

In the next section, we develop a grammatical theory of implicatures that builds on Marty's (2017) characterisation of assertion-based and presupposition-based implicatures. This characterisation maintains the original idea from Magri (2009) and Gajewski and Sharvit (2012) that exhaustification operates in the same way in the assertion and in the presupposition of a sentence while at the same time offering an account of the asymmetry in (4) along the lines of Spector and Sudo (2017). We will show that the resulting theory accounts for the parallels in (9)-(11) and provides a unified analysis of these inferences. In particular, we will show how this theory can directly account for PRESUPPOSED FREE CHOICE and, once combined with a grammatical account of ignorance inferences à la Meyer (2013), for PRESUPPOSED IGNORANCE as well. 


\section{Back to a unified grammatical approach}

\subsection{Ingredients of the account}

\subsubsection{Presupposed implicatures in the grammar}

The first part of our system follows and extends the grammatical view on presupposed implicatures recently proposed by Marty (2017). In the spirit of the grammatical approach we presented in Sect. 3.2, Marty's (2017) account is one on which assertion-based and presupposition-based implicatures are derived in the grammar by exhaustification, i.e. through the application of EXH. In contrast to previous grammatical approaches, however, it is hypothesised that the distinction between assertion-based and presupposition-based implicatures directly follows from the status of the alternatives under consideration, which is determined by the logical relationship between those alternatives and their base sentence. ${ }^{25}$

In essence, Marty proposes that the computation of the implicatures of a sentence $\phi_{p}$ is based on two sets of alternatives that are mutually exclusive and distinguished on the basis of Strawson-entailment: (i) a set of assertive alternatives, comprising those alternatives to $\phi_{p}$ that can consistently be false when $\phi_{p}$ is true, (56-a), and (ii) a set of presuppositional alternatives, comprising those alternatives to $\phi_{p}$ that can only be undefined when $\phi_{p}$ is true, (57-a). ${ }^{26}$ Said differently, the assertive alternatives are those alternatives that are neither logically entailed nor Strawson-entailed by the prejacent, while the presuppositional alternatives are those alternatives that are not logically entailed but that are Strawson-entailed by the prejacent. On this proposal, exclusion needs to be performed innocently on both sets of alternatives. For presuppositional alternatives, we adopt the procedure of innocent exclusion ( $\mathrm{IE}_{p r s}$ ) proposed in Marty (2017), (57-b), which applies Fox's (2007) notion to the presuppositional domain. For assertive alternatives, we propose that innocent exclusion $\left(\mathrm{IE}_{a s r}\right)$ is computed as shown in (56-b), by taking all maximal sets of assertive alternatives that can be negated consistently with the prejacent and the negation of the presupposition of all $\mathrm{IE}_{\text {prs }}$ alternatives. $^{27}$

\section{Assertive alternatives ( $\left.\mathbf{E}_{a s r}\right)$ and Innocent Exclusion ( $\left(\mathbf{E}_{a s r}\right)$}

a. $\mathrm{E}_{a s r}\left(\phi_{p}\right)=\left\{\psi_{q}: \psi_{q} \in \operatorname{ALT}\left(\phi_{p}\right)\right.$ and $\left.\phi_{p}, q \not \forall \psi_{q}\right\}$

\footnotetext{
25 As Marty (2017) discusses, in contrast to previous grammatical approaches, the core of this theory does not require the richness of a two-dimensional theory of meaning. We will follow here his implementation which assumes a uni-dimensional approach to meaning and uses partial semantics for presuppositions. This implementation is also shown in Marty (2017: Chapter 2) to address a number of over-generation issues encountered by a two-dimensional approach à la Magri (2009).

26 As is well known, there are various ways to define the notions of entailment and consistency in a trivalent or partial semantics. We assume here that entailment is defined as in (i) and that consistency is defined as in (ii). The negation used in our definitions is the so-called 'strong' negation. That is, $\neg \phi_{p}$ is defined only if $p$ is true and, where defined, $\neg \phi_{p}$ is true iff $\phi_{p}$ is false.

(i) $\quad \phi$ entails $\psi$ iff, for any world at which $\phi$ is true, $\psi$ is also true at that world.

(ii) A set of propositions $S$ is consistent iff all of its members can be true at the same world.

27 This second definition slightly departs from Marty (2017) in that it assumes that $\mathrm{IE}_{a s r}$ is computed on the basis of $I E_{\text {prs }}$ rather than independently.
} 
b. $\mathrm{IE}_{a s r}\left(\phi_{p}\right):=\bigcap$

$\left\{\begin{array}{l|l}S & \begin{array}{l}S \subseteq \mathrm{E}_{a s r}\left(\phi_{p}\right) \text { and } S \text { is a maximal subset of } \mathrm{E}_{a s r}\left(\phi_{p}\right) \text { such that } \\ \left\{\neg \psi_{q}: \psi_{q} \in S\right\} \cup\left\{\phi_{p}\right\} \cup\left\{\neg r: \chi_{r} \in \mathrm{IE}_{p r s}\left(\phi_{p}\right)\right\} \text { is consistent }\end{array}\end{array}\right\}$

\section{Presuppositional alternatives ( $\left.\mathbf{E}_{p r s}\right)$ and Innocent Exclusion (IE $\mathbf{E}_{p r s}$ )}

a. $\mathrm{E}_{p r s}\left(\phi_{p}\right)=\left\{\chi_{r}: \chi_{r} \in \operatorname{ALT}\left(\phi_{p}\right)\right.$ and $\phi_{p} \not \models \chi_{r}$ and $\left.\phi_{p}, r \models \chi_{r}\right\}$

b. $\mathrm{IE}_{p r s}\left(\phi_{p}\right):=\bigcap$

$\left\{\begin{array}{l|l}S^{\prime} & \begin{array}{l}S^{\prime} \subseteq \mathrm{E}_{p r s}\left(\phi_{p}\right) \text { and } S^{\prime} \text { is a maximal subset of } \mathrm{E}_{p r s}\left(\phi_{p}\right) \\ \text { such that }\left\{\neg r: \chi_{r} \in S^{\prime}\right\} \cup\left\{\phi_{p}\right\} \text { is consistent }\end{array}\end{array}\right\}$

Next, Marty (2017) proposes that the exhaustivity operator be defined as shown in (58). For clarity, we will notate this variant of the exhaustivity operator as ' $\mathrm{EXH}_{a s r+p r s}$, ${ }^{28}$

$$
\begin{aligned}
& \text { Exhaustivity for } \mathrm{IE}_{a s r} \text { and } \mathrm{IE}_{\text {prs }} \text { alternatives (Marty 2017, (62), p. 37) } \\
& \qquad \begin{aligned}
\llbracket \mathrm{EXH}_{\text {asr }+p r s} \phi_{p} \rrbracket=\lambda w & : p(w) \wedge \forall \psi_{q} \in \mathrm{IE}_{\text {asr }}[q(w)] \wedge \forall \chi_{r} \in \mathrm{IE}_{\text {prs }}[\neg r(w)] \\
& \cdot \llbracket \phi_{p} \rrbracket(w) \wedge \forall \psi_{q} \in \mathrm{IE}_{a s r}\left[\neg \llbracket \psi_{q} \rrbracket(w)\right]
\end{aligned}
\end{aligned}
$$

At the level of the assertion, $\mathrm{EXH}_{a s r+p r s}$ achieves the same results as the classical exhaustivity operator (see (15) for instance). However, $\mathrm{EXH}_{a s r}+$ prs further strengthens the definedness conditions (i.e., the presupposition) of its prejacent in two ways, achieving in effect similar results as Magri (2009) and Spector and Sudo (2017) combined. First, in line with Magri (2009), $\mathrm{EXH}_{a s r+p r s}$ presupposes the falsity of the presuppositions of the $\mathrm{IE}_{\text {prs }}$-alternatives to its prejacent. Second, in line with Spector and Sudo's (2017), EXH $\mathrm{EH}_{\text {as }+ \text { prs }}$ passes up to the whole sentence the presuppositions of the negated $\mathrm{IE}_{a s r}$-alternatives. To illustrate these different aspects of the working of $\mathrm{EXH}_{a s r+p r s}$, consider for instance the following sentence (adapted from Marty 2017) and imagine that it is uttered by a judge at the beginning of a trial, in which we have a defendant and a plaintiff:

A witness for the DEFENDANT is late.

$p:=$ the defendant has one or more witnesses

a. $\mathrm{ALT}_{\text {asr }}:=\{$ a witness for the plaintiff is late $\}$

$q:=$ the plaintiff has one or more witnesses

$\phi_{p}$

ALT $_{\text {prs }}:=\{$ the witness for the defendant is late $\}$

$r:=$ the defendant has a unique witness

This sentence has two potentially relevant alternatives, (59-a) and (59-b), each of which has a distinct status relative to (59). On the one hand, (59-a) is an assertive alternative to (59) since it can be false whenever (59) is true. One the other hand, (59-b) is a presuppositional alternative to (59) since it can be undefined, yet never false

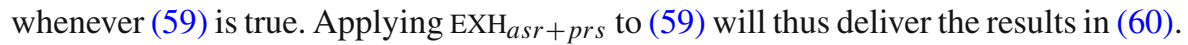
In a nutshell, (59)'s presupposition is strengthened first by adding the presupposition that the defendant doesn't have a unique witness (i.e., the negation of the uniqueness presupposition of (59-b)) and next by passing up the presupposition that the plaintiff

\footnotetext{
28 As is customary, we use the notation ' $\lambda \chi: \psi(\chi) . \phi$ ' to represent a function defined only for objects of which $\psi$ is true (convention from Kratzer and Heim 1998).
} 
has at least one witness (i.e., the existential presupposition of (59-a)). Finally, (59)'s assertion is strengthened by adding the assertion that no witnesses of the plaintiff is late (i.e., the negation of (59-a)).

$\mathrm{EXH}_{a s r+p r s}\left[\phi_{p}\right.$ a witness for the DEFENDANT is late]

a. PRESUPPOSITION

(i) the defendant has one or more witnesses, and

(ii) the defendant doesn't have a unique witness, and

(iii) the plaintiff has one or more witnesses.

b. ASSERTION

(i) a witness of the defendant is late, and

(ii) no witnessess of the plaintiff is late.

Now, we propose to refine the above account by extending the notion of innocent inclusion (Bar-Lev and Fox 2020; Bar-Lev 2018, see Sect. 2.3) to presuppositional alternatives as well. Concretely, we propose to keep Bar-Lev and Fox's (2020) characterisation of II-alternatives and to use it to define in this system the set of innocently includable assertive alternatives, (61-a). We add to this definition the corresponding one for innocently includable presuppositional alternatives in (61-b): the $\|_{p r s}$-alternatives to a sentence $\phi_{p}$ are those presuppositional alternatives to $\phi_{p}$ whose presupposition can be added to $\phi_{p}$ 's presupposition without conflicting with any of the potential presupposed implicatures arising from $\phi_{p}$ on the basis of the $\mathrm{IE}_{\text {prs }}$-alternatives. As before, we assume that the procedure for (including) presuppositional alternatives takes precedence over that for (including) assertive ones. That is, we require that the includable assertive alternatives be consistent not only with the assertive implicatures associated with the $\mathrm{IE}_{a s r}$-alternatives but also with the presupposed implicatures associated with the $\mathrm{II}_{\text {prs }}$-alternatives.

\section{Innocently Includable alternatives ( $\mathrm{II}_{a s r}$ and $\left.\mathrm{II}_{p r s}\right)$}

a. $\quad \mathrm{I}_{\text {asr }}\left(\phi_{p}\right):=\bigcap$

$$
\left\{\begin{array}{l|l}
S & \begin{array}{l}
S \subseteq \mathrm{E}_{a s r}\left(\phi_{p}\right) \text { and } S \text { is a maximal subset of } \mathrm{E}_{a s r}\left(\phi_{p}\right) \text { such that } \\
\left\{\xi_{s}: \xi_{s} \in S\right\} \cup\left\{\phi_{p}\right\} \cup\left\{\neg \psi_{q}: \psi_{q} \in \mathrm{IE}_{a s r}\left(\phi_{p}\right)\right\} \cup\left\{r: \chi_{r} \in \|^{p r s}\left(\phi_{p}\right)\right\} \\
\text { is consistent }
\end{array}
\end{array}\right\}
$$

b. $\quad \mathrm{II}_{p r s}\left(\phi_{p}\right):=\bigcap$

$$
\left\{\begin{array}{l|l}
S^{\prime} & \begin{array}{l}
S^{\prime} \subseteq \mathrm{E}_{p r s}\left(\phi_{p}\right) \text { and } S^{\prime} \text { is a maximal subset of } \mathrm{E}_{p r s}\left(\phi_{p}\right) \text { such that } \\
\left\{r: \chi_{r} \in S^{\prime}\right\} \cup\left\{\phi_{p}\right\} \cup\left\{\neg q: \psi_{q} \in \mathrm{IE}_{p r s}\left(\phi_{p}\right)\right\} \text { is consistent }
\end{array}
\end{array}\right\}
$$

The exhaustivity operator in (58) must be then revised so as to integrate the contribution of the newly defined $\mathrm{II}_{a s r}$ and $\mathrm{II}_{\text {prs }}$ alternatives to the outcome of exhaustification:

$$
\begin{aligned}
& \text { Exhaustivity for } \mathrm{IE}_{a s r}, \mathrm{II}_{a s r}, \mathrm{IE}_{p r s} \text {, and } \mathrm{II}_{p r s} \text { alternatives } \\
& \llbracket \mathrm{EXH}_{a s r+p r s}^{I E+I I} \phi_{p} \rrbracket=\lambda w \quad: p(w) \wedge \forall \chi_{r} \in\left(\mathrm{IE}_{a s r} \cup\left\|_{a s r} \cup\right\|_{p r s}\right)[r(w)] \wedge \forall \psi_{q} \in \mathbb{E}_{p r s}[\neg q(w)] \\
& \llbracket \phi_{p} \rrbracket(w) \wedge \forall \chi_{r} \in \mathbb{I}_{a s r}\left[\llbracket \chi_{r} \rrbracket(w)\right] \wedge \forall \psi_{q} \in \mathbb{I}_{a s r}\left[\neg \llbracket \psi_{q} \rrbracket(w)\right]
\end{aligned}
$$

At a general level, this exhaustivity operator can be thought of as the synthesis of the exhaustivity operator proposed in Marty (2017) and the one proposed in Bar-Lev 
and Fox (2020). In particular, it is easy to verify that, at the level of the assertion, $\mathrm{EXH}_{\text {asr }+ \text { prs }}^{I E+I I}$ reproduces the results of $\mathrm{EXH}^{I E+I I}$ in (24) and that, at the level of the presupposition, it preserves the results of $\mathrm{EXH}_{a s r+p r s}$ in (58). The novel feature of this operator is therefore solely concerned with the contribution of the II-alternatives at the presupposition level: (i) $\mathrm{EXH}_{a s r+p r s}^{I E+I I}$ passes up to the whole sentence the presuppositions of the $\mathrm{II}_{a s r}$-alternatives, just like it passes up the presupposition of the $\mathrm{IE}_{\text {asr }}$-alternatives, and (ii) $\mathrm{EXH}_{a s r+p r s}^{I E+I I}$ presupposes the truth of the presuppositions of the $I_{p r s}$-alternatives, which we take to be the presuppositional analog of conveying the truth of the $\mathrm{II}_{a s r}$-alternatives in the assertion. As we shall later see, this feature will play a critical role in accounting for the parallels observed between FREE CHOICE and PRESUPPOSED FREE CHOICE.

To complete the first part of our theory, we need now to clarify our assumptions about the distribution of the exhaustivity operator and the contextual factors affecting implicature-computation. Following Magri (2009, 2011, 2014, 2017), we assume that EXH can be inserted at any propositional node and that it is syntactically mandatory at matrix scope. ${ }^{29}$ In this framework, the domain of quantification of EXH is modulated by relevance and economy considerations, accounting for the context-dependency of implicatures. In the remainder of this section, we briefly review both kinds of considerations in turn.

As far as relevance is concerned, we adopt the basic assumptions from Magri (2009, 2011): (i) EXH requires its prejacent to be relevant and (ii) relevance is closed under contextual equivalence. Hence, if the prejacent $\phi_{p}$ of EXH is relevant, then any assertive alternative to $\phi_{p}$ that is contextually equivalent to $\phi_{p}$ is also relevant (of course, if $\phi_{p}$ is not relevant to begin with, then $\operatorname{EXH}\left(\phi_{p}\right)$ is predicted to be infelicitous). ${ }^{30} \mathrm{Next}$, we propose to extend this reasoning to presuppositional alternatives by assuming that, for these alternatives, relevance is assessed by considering the relevance of their presupposition (see Marty 2019: Section 4.3-4.4 for discussion). The rationale underlying this assumption is that the implicature associated with a presuppositional alternative $\psi_{q}$ is one that adds either $\neg q$ (if $\psi_{q}$ is excludable) or $q$ (if $\psi_{q}$ is includable) to the plain presupposition of their base sentence and, therefore, for the resulting implicature to be relevant, $\neg q$ or $q$ must be relevant. To put it differently, we propose that, for presuppositional alternatives, only the relevance of their presupposition matters for deciding whether or not a presupposed implicature is derived because their presupposition is the sole meaning component that is manipulated (excluded or included) by the exhaustification process.

An immediate consequence of this proposal is that if the presupposition of a presuppositional alternative to the prejacent $\phi_{p}$ of EXH is satisfied in the context of $\phi_{p}$, then that presupposition trivially counts as relevant in that context. To understand this

\footnotetext{
29 This assumption is extended in Magri (2011) and Marty (2017) from the matrix level to any embedded propositional level. For our immediate purposes, however, it is enough to assume that the exhaustivity operator is mandatory at matrix level since we will not be concerned with infelicity effects arising from the computation of conflicting embedded implicatures. We refer the reader to Mart (2017: Appendix A) for discussion of this assumption in the case of presupposed implicatures.

30 As it has already been pointed out in the literature, additional relevance considerations may affect implicature-computation in specific environments such as disjunctive sentences. These environments, and the refinements they call for, are discussed below in Sects. 5.1.3 and 5.2.3.
} 
point further, consider a notion of relevance modelled using questions under discussion (see Roberts 2004; Beaver and Clark 2009 among many others) and assume that the question under discussion is associated with a partition of the context set, which corresponds to the set of complete answers to this question (a.o., Heim 1994; Groenendijk et al. 1984; Groenendijk and Stokhof 1984; Bennett 1979). On this view, relevance can be defined as in (63), where $Q$ is the partition associated with the question under discussion: a proposition is relevant if and only if it does not distinguish between two worlds within a cell of $Q$.

Let $Q$ be a partition of the context set. A proposition $p$ is relevant given $Q$ iff for any cell $q \in Q$ and any two worlds $w, w^{\prime} \in q, p(w)=p\left(w^{\prime}\right)$.

Given (63), we have it that, if a proposition $p$ is entailed by the context set (e.g., if $p$ is a presupposition satisfied in the context) then, for any partition $Q$ of that context set, $p$ cannot distinguish between any world within any cell of $Q$, and therefore $p$ is relevant. ${ }^{31}$ It follows from the above that, if the prejacent $\phi_{p}$ of EXH is assertable at a context $c$ (i.e., if $c$ entails $p$ ), then $p$ is relevant in $c$ and so are the presuppositions of the presuppositional alternatives to $\phi_{p}$ that are satisfied in $c$. Conversely, if $\phi_{p}$ is not assertable to begin with, e.g., $p$ isn't met prior to utterance and fails to be accommodated, then $\operatorname{EXH}\left(\phi_{p}\right)$ is simply infelicitous. Crucially, if an assertive alternative or the presupposition of a presuppositional alternative is deemed relevant in that sense, it cannot be pruned from the domain of quantification of EXH; consequently, any assertive or presupposed implicature associated with such an alternative is predicted to be mandatory. ${ }^{32}$

Turning next to economy considerations, we assume that, if an alternative can be pruned from the domain of EXH, then it must be pruned if the implicature associated with that alternative would make the global meaning of the sentence weaker and thus decrease its overall informativeness. In our system, the economy constraint on EXH in (28) can be thus slightly modified as suggested in (64) so as to prevent EXH from applying if the resulting meaning would be asymmetrically Strawson-entailed by the base sentence without EXH. ${ }^{33}$

\footnotetext{
31 See Križ (2016) for a similar definition of the notion of answer to a question and related discussion.

32 The role of relevance in implicature-computation can be modelled à la Magri by assuming that, just like other universal quantifiers, the domain of EXH is restricted by a contextually assigned relevance predicate (usually notated $\mathcal{R}$ ). Note however that what is crucial to our account is the idea that, in order for an assertive or presuppositional alternative to enter implicature-computation, it need not only be innocently excludable or includable but also relevant (i.e., there is no point in excluding or including irrelevant meaning components).

33 The formulation in (64) is given for the sake of clarity, i.e., to make the parallel with (28) explicit. This formulation, however, is not well suited for our system since we assume that EXH is syntactially mandatory at certain positions (e.g., at matrix level). In our framework, the economy constraint at stake is to be thought instead as a regulating principle on pruning alternatives. One way to formulate it is as in (i). Note however that (64) and (i) lead to the same results.
}

\section{(i) Economy Constraint}

An alternative $A$ to a sentence of the form $\operatorname{EXH}(\operatorname{ALT})(S)$ is to be pruned from ALT if (i) $A$ is not obligatorily relevant in the context of $S$, and (ii) $\operatorname{EXH}\left(\operatorname{ALT}^{\prime}\right)(S)$ asymmetrically Strawson-entails $\operatorname{EXH}(\operatorname{ALT})(S)$, where $\operatorname{ALT}^{\prime}$ is ALT without $A$. 


\section{Economy Constraint (modification of (28))}

An occurrence of EXH in a sentence $\mathrm{S}$ is not licensed if the resulting meaning of S with that occurrence of EXH is asymmetrically Strawson-entailed by S without it.

Just like (28), the constraint in (64) correctly prevents the application of EXH in cases like (30) or (48), where EXH would otherwise weaken the meaning of the sentence in which it is inserted. Crucially, however, this constraint is more permissive than (28) since, unlike (28), it allows the application of EXH in cases where the resulting sentence is Strawson-equivalent to its counterpart without EXH. We will latter see that, on this approach, the derivation of PRESUPPOSED FREE CHOICE involve in fact such cases.

\subsubsection{Presupposed ignorance in the grammar}

The second part of our system builds on the grammatical approach to ignorance implicatures proposed in Meyer (2013) and extends it to presuppositions. In essence, this is done by refining the semantics of the Matrix $K$ operator in (17) as shown in (65) so as to offer a proper treatment of presuppositions. We note that this refinement simply corresponds to what is predicted by standard accounts of presupposition projection under attitude predicates (Heim 1992 among others). As far as the distribution of this operator is concerned, we adopt Meyer's (2013) Matrix $K$ Axiom: all assertively used sentences are covertly modalised by the global $K$ operator in (65). On these assumptions, an utterance of a sentence $\phi_{p}$ by a speaker $s$ is parsed at LF as $\left[K_{s} \phi_{p}\right]$, the semantic outcome of which presupposes that $s$ believes the presupposition $p$ of $\phi_{p}$ and asserts that $s$ believes $\phi_{p}$

$$
\llbracket K_{x} \phi_{p} \rrbracket=\lambda w: \forall w^{\prime} \in \operatorname{Dox}(x)(w)\left[p\left(w^{\prime}\right)\right] . \forall w^{\prime} \in \operatorname{Dox}(x)(w)\left[\llbracket \phi_{p} \rrbracket\left(w^{\prime}\right)\right]
$$

With our two operators in place, an utterance of the surface form $\phi_{p}$ is to be mapped in our system onto an LF like that in (66-a) or else like that in (66-b). The availability of these two parses directly follows from our assumption that the presence of EXH is syntactially mandatory above $K$ while it is optional below $K .^{34}$

$$
\begin{array}{ll}
\text { a. } & {\left[\operatorname{EXH}\left[K_{s}\left[\phi_{p}\right]\right]\right]} \\
\text { b. } & {\left[\operatorname{EXH}\left[K_{s}\left[\operatorname{EXH}\left[\phi_{p}\right]\right]\right]\right]}
\end{array}
$$

As we have seen, on Meyer's proposal, the interactions between EXH and $K$ account for the pattern of inferences associated with simple disjunctive sentences, i.e., for the EXCLUSIVITY and IGNORANCE implicatures that these sentences give rise to. In the next section, we will see that our extended system permits to reproduce these good results for the presuppositional counterparts of these implicatures. For the time being, let us simply emphasize another important feature of this system which is directly inherited from Meyer's approach: the scopal interactions between EXH and $K$ permit us to account for subtle variations in the logical strength of the assertion-based and presupposition-based implicatures accessed by speakers. To illustrate this feature,

\footnotetext{
34 For simplicity, we will leave out the superscripts and subscripts of our exhaustivity operator $\mathrm{EXH}_{a s r+p r s}^{I E+I I}$ (see (62) for definition) and simply call it EXH in the following.
} 
consider first an utterance of Some of the students smoke which, on our assumptions, can have one of the following two LFs:

$\mathrm{EXH}_{(1)}\left[K_{S}\right.$ [some of the students smoke]]

$\operatorname{ALT}_{\text {asr }}(1)=\left\{\left[K_{s}\right.\right.$ [all of the students smoke $\left.\left.]\right]\right\}$

$\mathrm{EXH}_{(1)}\left[K_{S}\left[\mathrm{EXH}_{(2)}\right.\right.$ [some of the students smoke]]]

a. $\operatorname{ALT}_{a s r}(2)=\{[$ all of the students smoke $]\}$

b. $\operatorname{ALT}_{a s r}(1)=\left\{\left[K_{s}\left[\mathrm{EXH}_{(2)}\right.\right.\right.$ [all of the students smoke $\left.\left.]\right]\right]$, $\left[K_{S}\right.$ [all of the students smoke] $\left.]\right\}$

The first LF in (67) is an instance of the parse in (66-a). On this parse, the meaning of EXH's prejacent can be exhaustified on the basis of its modalised all-alternative, generating a so-called primary implicature compatible with a state of ignorance: the speaker does not believe that all the students smoke, (69-a). There is another interpretive option, the second LF in (68), which corresponds to the parse in (66-b). On this parse, the meaning of the target sentence can be exhaustified at the level of $\mathrm{EXH}_{(2)}$ on the basis of the non-modalised all-alternative in (68-a), generating then a so-called secondary implicature that attributes to the speaker a state of certainty towards the alternative it is based on: the speaker believes that not all the students smoke, (69-b). Note that the derivation of this implicature renders the working of $\mathrm{EXH}_{(1)}$ in (68) vacuous since $\mathrm{EXH}_{(1)}$ 's prejacent already entails the primary implicatures that could be derived on the basis of the assertive alternatives in (68-b).

a. Primary assertion-based implicature through $\mathrm{EXH}_{(1)}$ : $K_{S}$ (some of the students smoke) $\wedge \neg K_{S}$ (all of the students smoke)

b. Secondary assertion-based implicature through $\mathrm{EXH}_{(2)}$ : $K_{S}$ (some of the students smoke $) \wedge K_{S} \neg($ all of the students smoke)

For what is most relevant here, these results naturally extend to presupposition-based implicatures on our account. Consider for instance an utterance of A brother of John smokes, the plain meaning of which merely presupposes that John has at least one brother. In our system, this utterance can be parsed at LF either as in (70) or as in (71).

$\mathrm{EXH}_{(1)}\left[K_{S}\right.$ [a brother of John smokes]]

$\operatorname{ALT}_{\text {prs }}(1)=\left\{\left[K_{s}\right.\right.$ [John's brother smokes $\left.\left.]\right]\right\}$

$\mathrm{EXH}_{(1)}\left[K_{S}\left[\mathrm{EXH}_{(2)}[\right.\right.$ a brother of John smokes $\left.\left.]\right]\right]$

a. $\operatorname{ALT}_{\text {prs }}($ (2) $)=\{[$ John's brother smokes $]\}$

b. $\operatorname{ALT}_{\text {prs }}(1)=\left\{\left[K_{s}\left[\mathrm{EXH}_{(2)}[\right.\right.\right.$ John's brother smokes $\left.\left.]\right]\right]$, $\left[K_{s}[\right.$ John's brother smokes]]\}

As it has long been observed (a.o., Sauerland 2008; Chemla 2008; Heim 1991; Rouillard and Schwarz 2017; Elliott and Sauerland 2019), the non-uniqueness implicature associated with such an utterance can be more or less strong depending on the context and take one of two forms: it can convey that the speaker cannot take for granted that John has just one brother (primary implicature), e.g., because she is ignorant about that 
matter, or instead that the speaker takes for granted that John has more than just one brother (secondary implicature). Our account straightforwardly captures these possible variations in the logical strength of presupposition-based implicatures: the weaker form of this inference is derived by exhaustifying the meaning of the target sentence only at the level of $\mathrm{EXH}_{(1)}$ on the basis of the presuppositional alternative in (70), as shown in (72-a), while its stronger form is derived by doing so at the level of $\mathrm{EXH}_{(2)}$ on the basis of the presuppositional alternative in (71-a), as shown in (72-b). ${ }^{35}$

a. Primary presupposition-based implicature through $\mathrm{EXH}_{(1)}$ :

$K_{S}$ (John has a brother) $\wedge \neg K_{S}$ (John has a unique brother $)$

b. Secondary presupposition-based implicature through $\mathrm{EXH}_{(2)}$ : $K_{S}($ John has a brother $) \wedge K_{S} \neg($ John has a unique brother $)$

Our system thus offers a uniform account of the commonly observed variations in the strength of assertion-based and presupposition-based implicatures by deriving both their primary and secondary forms in the grammar. Specifically, for any utterance $\phi_{p}$ produced by a speaker $s$, any alternative $\psi_{q} \in \mathrm{IE}_{a s r}\left(\phi_{p}\right)$ and any alternative $\chi_{r} \in \mathrm{IE}_{\text {prs }}\left(\phi_{p}\right)$, our system is able to generate presupposition-based implicatures of the form $K_{s}(\neg r)$ or $\neg K_{s}(r)$, which are themselves presuppositions, in addition to assertion-based implicatures of the form $K_{s}\left(\neg \psi_{q}\right)$ or $\neg K_{s}\left(\psi_{q}\right)$, which also add their presupposition $q$. In this system, pragmatics is the sum of principles that guide the decision process to compute an implicature of a particular strength at a given context. As on other approaches to scalar implicatures, we take this process to be guided among other things by one's understanding of what is relevant in context and one's assumptions about the speaker's epistemic state. In the next subsection, we review the core conditions under which the computation of an implicature becomes mandatory and can give rise to representations that contradict common knowledge.

\subsubsection{Mandatory implicatures and contextual mismatches}

Before we turn to the empirical scope of our theory, we need to emphasize one last important feature of the system we devised: it is a conservative extension of the theory of oddness originally developed in Magri (2009, 2011, 2014), later pursued in Schlenker (2012) and fully extended to presuppositional effects in Marty (2017). On this theory, the infelicity of sentences like (73)-(74) results from the mandatory computation of a mismatching implicature, that is an obligatory implicature which contradicts common knowledge.

The general logic underlying this process goes as follows. First, the domain of quantification of EXH is constrained by a contextually assigned relevance predicate $\mathcal{R}$ (see 5.1.1 and footnote 32), hence the notation $\mathrm{EXH}_{\mathcal{R}}$. Second, the denotation of $\mathrm{EXH}_{\mathcal{R}}$ requires that its prejacent $\phi_{p}$ be relevant, that is [ $\mathrm{EXH}_{\mathcal{R}} \phi_{p}$ ] presupposes $\phi_{p} \in \mathcal{R}$. Third, since relevance is closed under contextual equivalence, it follows that any assertive

\footnotetext{
35 A similar proposal for deriving secondary presupposition-based implicatures in the grammar has recently been made in Elliott and Sauerland (2019). These authors show how this proposal addresses Heim's (1991) original observation that the inferences derived from Maximize Presupposition! may have a so-called 'weak' epistemic status.
} 
alternative $\psi_{q}$ to $\phi_{p}$ that is contextually equivalent to $\phi_{p}$ is also relevant. Finally, for presuppositional alternatives, relevance is assessed by considering their presuppositional contribution; since any proposition that is entailed by the context trivially counts as relevant, any presupposition $r$ of a presuppositional alternative $\chi_{r}$ to $\phi_{p}$ that is already common ground must be relevant. ${ }^{36}$ In sentences like (73)-(74), we have it that the alternatives to EXH's prejacent are relevant and, consequently the implicatures associated with them become mandatory, resulting in contextual mismatches, hence the oddness of these examples. ${ }^{37}$

(73) \#Some Italians come from a beautiful country.

a. Parse: $\operatorname{EXH}_{\mathcal{R}}\left[\phi_{p}\right.$ some Italians come from a beautiful country]

b. Alternative: $\quad\left[\psi_{q}\right.$ all Italians come from a beautiful country]

c. Relevance: $\quad \psi_{q} \Leftrightarrow_{c} \phi_{p}$ and so $\psi_{q} \in \mathcal{R}$

d. Implicature: \#Not all Italians come from a beautiful country

(74) \#A sun is rising.
a. Parse: $\operatorname{EXH}_{\mathcal{R}}\left[\phi_{p}\right.$ a sun is rising]
b. Alternative: $\quad\left[\chi_{r}\right.$ the sun is rising $]$
c. Relevance: $\quad c \subseteq r$ and so $r \in \mathcal{R}$
d. Implicature: \#There isn't a unique sun

Here we aim at establishing two things. First, the above results are fully preserved in our extended exhaustivity-based framework that integrates the Matrix $K$ operator (for similar suggestions see Meyer 2013, 2014 for assertion-based implicatures and Elliott and Sauerland 2019 for presupposition-based implicatures). Second, our system leaves room for further mismatching implicatures to arise due to the interactions between EXH and $K$. To establish the first point, consider the parses in (75) and (76) which correspond to the most minimal LFs that are predicted by our system for the sentences in (73) and (74), respectively:

$$
\begin{aligned}
& \operatorname{EXH}_{\mathcal{R}}\left[\phi_{p} K_{s}\right. \text { [some Italians come from a beautiful country]] } \\
& \text { a. Alternative: } \quad\left[\psi_{q} K_{s}\right. \text { [all Italians come from a beautiful country]] } \\
& \text { b. Relevance: } \quad \psi_{q} \Leftrightarrow_{c} \phi_{p} \text { and so } \psi_{q} \in \mathcal{R} \\
& \text { c. Implicature: \#The speaker doesn't believe that all Italians come from a } \\
& \text { beautiful country (and thus that all Italians come from the same country) }
\end{aligned}
$$

\footnotetext{
36 Suitable algorithms for computing the domain restriction $\mathcal{R}$ as well as evaluating contextual equivalence at embedded levels are discussed in Schlenker (2012: Sections 4.1 and 4.2.1) and Marty (2017: Appendix A) based on the original proposal in Singh (2011).

37 We take it that the severity of the oddity effects arising from these sentences comes partly from the computation of a mismatching implicature and partly from the fact that the surprising piece of information is conveyed by the implicit, strengthened meaning of these sentences as opposed to be explicitly expressed by overt materials and flagged as a controversial contribution, one that may be debated and may not be accepted by all interlocutors (after all, accepting these sentences would require a substantial revision of the interlocutors' common assumptions about the world). In particular, we note that the overt counterparts of those implicit meanings, e.g. Some but not all Italians come from a beautiful country, albeit slightly odd, does not seem to give rise to such strong effects, arguably because the controversial piece of information is now put forward and left up for further conversational developments (e.g., explanation and disagreement).
} 
(76)

$\operatorname{EXH}_{\mathcal{R}}\left[\phi_{p} K_{s}\right.$ [a sun is rising]]
a. Alternative:
$\left[\chi_{r} K_{s}\right.$ [the sun is rising] $]$
b. Relevance:
$c \subseteq r$ and so $r \in \mathcal{R}$
c. Implicature:
\#The speaker doesn't believe that there is a unique sun

Just as before, these examples are predicted to give rise to mismatching implicatures. In (75) for instance, on the shared assumption that all Italians come from the same country, that the speaker believes that some Italians come from a beautiful country contextually entails that she believes that all Italians do and vice versa. Hence, we get for (75) the following outcome: $K_{S}$ (some Italians come from a beautiful country) $\wedge$ $\neg K_{S}$ (all Italians come from a beautiful country). The very same reasoning applies in (76) where, on the shared assumption that there is a unique sun, the application of EXH above $K$ mandatorily gives rise to a mismatching primary implicature. In sum, for these cases, our approach simply reproduces the classical results from previous exhaustivity-based accounts.

Yet there are also cases where our approach makes novel predictions and captures oddity effects that are beyond the explanatory scope of these previous accounts. Among them are the oddity effects triggered by mismatching ignorance implicatures arising from disjunctive sentences. Recall from our discussion of the examples in (51) that a sentence like (77) is deemed deviant because it gives rise to ignorance implicatures that contradict the contextual assumption that one should be knowledgeable about the personal facts at hand:

(77) \#My wife speaks French or Italian.

a. $\sim \# I_{s}$ (the speaker's wife speaks French)

b. $\sim \# I_{S}$ (the speaker's wife speaks Italian)

In a grammatical system without the Matrix $K$ operator, the oddness of these sentences is left to additional pragmatic principles like MQ. This is because a disjunctive sentence like (77) has only one innocently excludable alternative of immediate interest, its conjunctive alternative, and computing the implicature associated with that alternative only gives us that the speaker's wife doesn't speak both French and Italian, (78), a piece of information which is unproblematic and thus cannot account for the oddness of (77).

$\mathrm{EXH}_{\mathcal{R}}$ [my wife speaks French or Italian]

a. $\mathrm{IE}_{a s r}=\{[$ FRENCH AND ITALIAN $]\}$

b. $\sim$ [FRENCH OR ITALIAN $] \wedge \neg[$ FRENCH AND ITALIAN]

But consider now the most minimal parse of (77) that is predicted on our approach (for our purposes, we can set aside the modalised conjunctive alternative here):

$\left[\mathrm{EXH}_{\mathcal{R}}\left[K_{s}\right.\right.$ [my wife speaks French or Italian]]]

a. $\quad \mathrm{IE}_{a s r}=\left\{\left[K_{s}[\mathrm{FRENCH}]\right],\left[K_{s}[\right.\right.$ ITALIAN $\left.\left.]\right]\right\}$

b. $\sim K_{S}[$ FRENCH OR ITALIAN $] \wedge I_{S}[$ FRENCH $] \wedge I_{S}[$ ITALIAN $]$ 
At the matrix level, both modalised disjuncts are innocently excludable alternatives to EXH's prejacent. Computing the implicatures associated with these alternatives gives rise, together with the truth of EXH's prejacent, to the ignorance inferences we are after: if $K_{s}$ (FRENCH OR ITALIAN), $\neg K_{s}\left(\right.$ FRENCH) and $\neg K_{s}$ (ITALIAN), then $I_{s}$ (FRENCH) and $I_{S}$ (ITALIAN). As we have already established, the mandatory computation of such mismatching implicatures would account for the oddness of (77). One question yet remains to be addressed: since the assertive alternatives in (79) are not contextually equivalent to EXH's prejacent, what forces then the computation of these implicatures? That is, why can't these alternatives simply be pruned from the domain of quantification of EXH?

Recall that, in our system, the only way an implicature can be avoided is if the alternative it is based on can be pruned from $\mathcal{R}$, the set of relevant propositions. So far, we have only discussed two general constraints on pruning, one pertaining to assertive alternatives and the other pertaining to the presupposition of presuppositional alternatives. As is well known, however, certain environments like disjunctions or conditionals impose additional relevance-based constraints by virtue of their intrinsic properties (for discussion, see Simons 2001a; Fox 2007; Singh 2008; Fox and Katzir 2011). In particular, Simons (2001a) argues that, for a disjunction to be felicitous, its disjuncts have to be understood as relevant alternatives. That is, whenever a disjunction is relevant, so are its disjuncts. In our system, this proposal translates as: neither of the disjuncts can be pruned from $\mathcal{R}$ if the whole disjunction is itself in $\mathcal{R}$. As Simons discusses, this proposal can account for the fact that disjunctions with unrelated disjuncts are generally infelicitous, as exemplified in (80).

(80) ??Either there is dirt in the fuel line or it is raining in Tel-Aviv.

(cf. There is dirt in the fuel line and it is raining in Tel-Aviv)

We adopt here this line of explanation to account for the observation that disjunctions give rise to obligatory ignorance inferences in normal conversational situations, and in particular to account for the mandatory computation of the mismatching implicatures in (77). ${ }^{38}$ We will argue in Sect.5.2.3 that this restriction on pruning

\begin{abstract}
38 There are two main exceptions to this generalisation. The first one is when a disjunction is understood as an answer to a Yes-No question. In a conversation like (i) for instance, the partition associated with A's question has two cells, one in which the candidate didn't take either class and one in which she took at least one class, possibly both. Given this partition, the whole disjunction is relevant, but neither of the independent disjuncts needs to be so. Crucially, however, no exclusivity or ignorance implicature is intuitively drawn from B's answer. Some evidence for that is that B's answer can be developed by saying Yes she did! She took Logic whereas such continuations are normally infelicitous (e.g., The candidate took Logic or Algebra. \#(In fact,) She took Logic.)
\end{abstract}

(i) A: Did the candidate take Logic or Algebra?

B: Yes she did (take Logic or Algebra)!

The other main exception would be cases like (ii). These are also cases where no ignorance implicatures are intuitively drawn (rather the hearer will conclude here that Olivia took Logic, given the evident falsity of the second disjunct; see Simons 2001b; Chemla 2010 among others).

(ii) Either Olivia took Logic, or I'm the King of France.

In sum, it is not always true that the disjuncts of a disjunction are relevant when the whole disjunction is. Yet Simons' generalisation holds of all the cases which matter for us, i.e., the cases in which ignorance inferences are derived from the disjunctive sentence (and are not cancellable). 
extends to disjunctive presuppositions, accounting for our novel cases of presupposed ignorance.

\subsection{Empirical scope of the account}

\subsubsection{Factive presuppositions and the asymmetry}

We start by showing that our proposal provides an empirically adequate account of the generation and distribution of presupposed implicatures in factive environments. For these purposes, consider again the case of EXCLUSIVITY implicatures:

(9) Exclusivity and Presupposed Exclusivity

a. Olivia took Logic or Algebra. $\sim$ Olivia didn't take both Logic and Algebra

b. Noah is unaware that Olivia took Logic or Algebra. $\sim$ Olivia didn't take both Logic and Algebra

As we explained, the EXCLUSIVITY implicatures in (9) are identical in all but one important aspect: this implicature arises in (9-a) in the assertion, while it arises in (9-b) in the presupposition, leaving the assertion unaffected. These similarities and differences are immediately accounted for on our proposal. Ignoring for now the $K$ layer (which we go back to below), the EXCLUSIVITY implicatures in (9) are both derived in our system on the basis of the conjunctive alternatives to the sentences at hand. Crucially, however, these conjunctive alternatives have a different logical status in both cases and consequently, upon exhaustification, contribute to strengthen the meaning of their base sentence in different ways. As before, the conjunctive alternative to (9-a) is an assertive alternative to (9-a). Therefore, upon exhaustification, (9-a)'s meaning is strengthened by adding to its plain assertion the falsity of the assertion of its assertive alternative:

$\operatorname{EXH}_{\mathcal{R}}$ [Olivia took Logic or Algebra]

a. $\mathrm{IE}_{a s r}=\{[$ Olivia took Logic and Algebra $]\}$

b. STRENGTHENED ASSERTION:

(Olivia took Logic or Algebra) $\wedge \neg($ Olivia took Logic and Algebra)

In the second case, however, the corresponding conjunctive alternative is a presuppositional alternative to EXH's prejacent. Indeed, Noah is unaware that Olivia took Logic or Algebra is logically weaker than but Strawson-entailed by Noah is unaware that Olivia took Logic and Algebra, consistent with our characterisation of presuppositional alternatives (see (57)). As a result, (9-b)'s meaning is strengthened by adding to its plain presupposition the falsity of the presupposition of its presuppositional alternative. The resulting EXCLUSIVITY implicature is in essence the same as in (9-a), but it is now in the presupposition:

$\mathrm{EXH}_{\mathcal{R}}$ [Noah is unaware that Olivia took Logic or Algebra]

a. $\mathrm{IE}_{\text {prs }}=\{[$ Noah is unaware that Olivia took Logic and Algebra $]\}$ 
b. STRENGTHENED PRESUPPOSITION:

(Olivia took Logic or Algebra) $\wedge \neg($ Olivia took Logic and Algebra)

For completeness, we mention two additional results pertaining to the generality of our system. First, the integration of Meyer's (2013) $K$-operator and its extension to presuppositions makes it possible to derive instead the weaker, primary implicatures associated with the above alternatives. This result is achieved as before by assuming an LF with an occurrence of EXH above K, as illustrated in (83) and (84).

$\operatorname{EXH}_{\mathcal{R}}\left[K_{s}\right.$ [Olivia took Logic or Algebra]]

a. $\mathrm{IE}_{a s r}=\left\{\left[K_{s}\right.\right.$ [Olivia took Logic and Algebra $\left.]\right\}$

b. STRENGTHENED ASSERTION:

$K_{S}$ (Olivia took Logic or Algebra $) \wedge \neg K_{S}$ (Olivia took Logic and Algebra)

(84) $\operatorname{EXH}_{\mathcal{R}}\left[K_{s}\right.$ [Noah is unaware that Olivia took Logic or Algebra]]

a. $\mathrm{IE}_{p r s}=\left\{\left[K_{s}\right.\right.$ [Noah is unaware that Olivia took Logic and Algebra $\left.]\right\}$

b. STRENGTHENED PRESUPPOSITION:

$K_{S}($ Olivia took Logic or Algebra $) \wedge \neg K_{s}$ (Olivia took Logic and Algebra)

Second, our proposal naturally extends to other factive environments and other embedded scalars. For instance, the not-all implicature associated with a sentence like (85-a) follows from the exhaustification process we described in (81) while its presuppositional version in (85-b) follows from the one we described in (82).

a. Some of the students took Logic.

STRENGTHENED ASSERTION:

$\sim$ some but not all of the students took Logic

b. Noah didn't realize that some of the students took Logic STRENGTHENED PRESUPPOSITION: $\sim$ some but not all of the students took Logic

In sum, our proposal replicates so far the good results of previous grammatical approaches in full generality. What we shall now see is that it improves upon those previous approaches by accounting for the puzzling contrast in (37) discussed in Spector and Sudo (2017):

(37) CONTEXT: The interlocutors know that all of the students took Logic; Noah, however, has no idea that Logic is very popular among the students.

a. Noah is aware that SOME of the students took Logic.

b. \#Noah is unaware that SOME of the students Logic.

In our system, the source of this contrast is to be found in the different status of the target all-alternatives in both cases. In (37-b), on the one hand, the target allalternative is a presuppositional alternative to EXH's prejacent: upon exhaustification, the negation of its (stronger) presupposition can be added to the plain presupposition of EXH's prejacent. In the present case, since the presupposition of that alternative is satisfied in the assumed context, it is relevant. The strengthening process becomes 
therefore mandatory and results in a contextual contradiction, as shown in (86), hence the infelicity of (37-b). ${ }^{39}$

(86) \#Noah is unaware that some of the students took Logic.

a. Parse: $\operatorname{EXH}_{\mathcal{R}}\left[\phi_{p}\right.$ Noah is unaware that some of the students took Logic]

b. IE $\mathrm{E}_{\text {prs }}$ : $\quad\left[\chi_{r}\right.$ Noah is unaware that all of the students took Logic]

c. Relevance: $\quad r \in \mathcal{R}$ and so pruning $\chi_{r}$ from $\mathcal{R}$ is not possible

d. Implicature: \#Not all the students took Logic

In (37-a), on the other hand, the corresponding all-alternative is an assertive alternative to EXH's prejacent: upon exhaustification, its (stronger) presupposition and the negation of its assertion can be added all together to the plain meaning of EXH's prejacent. In the present case, since EXH's prejacent is not contextually equivalent to its all-alternative, this strengthening is yet predicted on our proposal to remain optional.

Noah is aware that some of the students took Logic.

a. Parse: $\operatorname{EXH}_{\mathcal{R}}\left[\phi_{p}\right.$ Noah is aware that some of the students took Logic]

b. IE $\mathrm{E}_{a s r}$ : $\quad\left[\psi_{q}\right.$ Noah is aware that all of the students took Logic $]$

c. Relevance: $\quad \psi_{q} \oiint_{c} \phi_{p}$ and so pruning $\psi_{q}$ from $\mathcal{R}$ is possible

d. Implicature: John is not aware that all the students took Logic (presupposing then that all the students took Logic)

Our account of the contrast in (37) is thus very similar to Spector and Sudo's (2017). In particular, both accounts predict the sentence in (37-b) to be odd due to the mandatory generation of some conflicting inference (attributed to the working of the PIP in one case, and to the working of EXH in the other), while no such conflict need to arise in (37-a). We note however that the two accounts make different predictions regarding three issues surrounding the felicity conditions of these and related cases. The first issue has to do with focus sensitivity. As we mentioned, $S \& S$ argue that, in a context in which it is known that all of the students took Logic, the scalar term some needs to be stressed in order for (37-a) to be felicitous. That is, while (88-a) is felicitous in such contexts, (88-b) isn't:

CONTEXT: It is common knowledge that all of the students took Logic.

\footnotetext{
the most minimal LFs for the sentences in (37) are in fact as shown in (i):
a. $\operatorname{EXH}_{\mathcal{R}}\left[K_{S}\right.$ [Noah is aware that some of the students took Logic]]
$\mathrm{IE}_{\text {asr }}: \quad\left[K_{S}\right.$ [Noah is aware that all of the students took Logic]]
b. $\operatorname{EXH}_{\mathcal{R}}\left[K_{S}\right.$ [Noah is unaware that some of the students took Logic]]

$\mathrm{IE}_{\text {prs }}: \quad\left[K_{S}\right.$ [Noah is unaware that all of the students took Logic]]
}

39 For presentation purposes, we are setting aside here the interactions between EXH and $K$. In our system,

These LFs deliver yet the same core results as the ones we use as working examples. In particular, the implicatures generated by these LFs can account by themselves for the contrast in (37): (i-a) may only give rise to the assertion-based implicature $\neg K_{S}$ (Noah is aware that all of the students took Logic), consistent with common knowledge, while (i-b) must give rise to the presupposition-based implicature $\neg K_{S}$ (all of the students took Logic), in conflict with common knowledge. This refinement may thus make a difference for (i-a) regarding the strength of the derived implicature, but it doesn't make any difference for (i-b) which is still predicted to give rise to a mismatching implicature. 
a. Noah is aware that SOME of the students took Logic.

b. \#Noah is aware that some of the students took Logic.

On S\&S's approach, this contrast is explained if one assumes that prosodic prominence on the scalar term strongly correlates with the presence of EXH. In (88-a), since some is stressed, scalar strengthening happens and the sentence is predicted to be felicitous. In (88-b), by contrast, some isn't stressed and, in the absence of scalar strengthening, the sentence is predicted to be infelicitous through the PIP. On our approach, on the other hand, the relevant implicature is predicted to remain optional in both cases given the absence of contextual equivalence with the target alternative. This approach can thus account for the fact that stress on some, signaling the active work of EXH, is the most natural choice in the given context. It can also account for why (88-b) is felicitous in a context in which it is not known that all of the students smoke. However, it does not readily account for the infelicity of (88-b). The contrast in (88) seems therefore to favour S\&S's approach.

The second issue also pertains to the status of the implicature in (37-a); this time, however, it is our approach which appears to make the right prediction. Specifically, Spector and Sudo's (2017) account predicts that, for (37-a) to be felicitous in the context at hand, an implicature must be computed to avoid the PIP from generating a contextual contradiction. By contrast, our account predicts (87) to be felicitous in that same context independently from such a strengthening process. With this in mind, consider the example in (89):

CONTEXT: The interlocutors know that all of the students took Logic.

I really don't know whether Noah is aware that all the students took Logic.

But he is aware that some of them did (took Logic).

$\chi_{\rightarrow} \neg$ (Noah is aware that all the students took Logic)

As before, the above context is one in which it is common ground that all of the students took Logic. However, the speaker is now explicitly stating that he is ignorant as to whether Noah is aware that all the students took Logic, and this information subsequently leads one to suspend the implicature previously associated with (37-a) (emphasized in italics in (89)). Crucially, we observe that the suspension of that implicature leaves the felicity of (37-a) unaffected. While this novel observation is in line with our predictions, it is problematic for Spector and Sudo (2017): in the absence of the target implicature, the PIP should apply just as in (37-b), and therefore the discourse in (89) should be perceived as infelicitous, contra speakers' intuitions. We conclude then that the test case in (89) supports our account, while it calls for further explanation on Spector and Sudo's (2017).

Finally, in contrast to S\&S's account, our account straightforwardly extends to contrasts like the one in (90):

(90) CONTEXT: It is common knowledge that all of the students took Logic and that Noah doesn't know it.

a. Noah discovered that SOME of the students took Logic.

b. \#Noah didn't discover that SOME of the students took Logic. 
As S\&S discuss, these sentences have more complex presuppositions than those involving (un)aware: they presuppose that (i) some of the students took Logic, and that (ii) it's not true that Noah believed (before discovering it) that some of the students took Logic. Crucially, the second part of this presupposition changes the nature of the logical relationship with the presupposition of the all-alternatives to these sentences. In particular, the presupposition of the all-alternative to (90-b) in (91) is that (i) all of the students took Logic, and that (ii) it's not true that Noah believed that all of the students took Logic. This presupposition is not stronger than that of (90-b), but logically independent. As a result, the PIP does not apply in this case and, thus, the oddness of $(90-b)$ is not predicted.

Noah didn't discover that all of the students took Logic.

By contrast, our account predicts the infelicity of (90-b). First, the sentence in (91) is a presuppositional alternative to (90-b); second, the presupposition of (91) is satisfied in the context in (90) and therefore relevant; finally, the exclusion of (91)'s presupposition gives rise to the presupposed implicature in (92), which conflicts with the assumed context. $^{40}$

Either not all of the students took Logic or Noah believed that all of them did.

To summarise, our proposal improves upon past grammatical approaches in offering a satisfying solution to the challenge raised by the contrast in (37) and related cases like (90). In contrast to Spector and Sudo's (2017) proposal, these results are achieved here in a fully grammatical system, without need for a separate principle like the PIP.

\subsubsection{Presupposed free choice}

Basic cases Let us now go back to presupposed free choice, repeated in (93) with its schematic representation, and let us illustrate how it is accounted for on our proposal.

$$
\text { Noah is unaware that Olivia can take Logic or Algebra. }[\neg \square[\diamond[\mathrm{L} \vee A]]] \diamond[\mathrm{L} \vee A]
$$

Recall that, in our system, the logically non-weaker alternatives to a given sentence are divided into two sets: its assertive alternatives and its presuppositional ones. It is easy to see that among the formal alternatives to (93) already considered above in (44), those that are logically non-weaker than (93) are also Strawson-entailed by (93) and therefore qualify as presuppositional alternatives, (94). ${ }^{41}$

\footnotetext{
40 Just like Spector and Sudo (2017), we predict (90-a) to be felicitous on its strengthened meaning in the assumed context. However, for the reasons we discussed in the first issue above, we do not readily predict this sentence to be odd in that same context when some is not stressed.

41 For simplicity, we will ignore again the conjunctive alternative to (93), that is Noah is unaware that Olivia can take Logic and Algebra. As the reader can verify, if we were to add this alternative, the resulting strengthened presupposition would be stronger, conveying further that Olivia cannot take both Logic and Algebra. The situation here is again parallel to what we see at the assertion level: the conjunctive alternative to Olivia can take Logic or Algebra gives rise to the inference that Olivia cannot take both Logic and Algebra. The prediction in both cases is that this inference should only arise when the conjunctive alternative is relevant; when this alternative is instead irrelevant, it will be pruned from the domain of EXH and the corresponding inference will not arise; see Fox (2007), Bar-Lev (2018) among others for discussion.
} 


$$
\operatorname{ALT}_{\text {prs }}((93)):=\left\{\begin{array}{l}
\text { Noah is unaware that O can take } \mathrm{L}[\neg \square[\diamond \mathrm{L}]] \diamond \mathrm{L} \\
\text { Noah is unaware that } \mathrm{O} \text { can take } \mathrm{A}[\neg \square[\diamond \mathrm{A}]]_{\diamond \mathrm{A}}
\end{array}\right\}
$$

If we apply now our exhaustivity operator to (93), we obtain the following LF (ignoring for now the additional $K$ layer, to which we go back to below):

$$
\mathrm{EXH}_{\text {asr }+ \text { prs }}^{I E+I I} \text { [Noah is unaware that Olivia can take Logic or Algebra] }
$$

What is the outcome of (95)? Or, to put it differently, how is (93)'s meaning strengthened on our approach? Since (93) has no assertive alternatives, the plain assertion of (93) will remain as it is. However, (93) has the presuppositional alternatives in (94). Those alternatives are not innocently excludable, but they are both innocently includable: it is possible to consistently add their presuppositions to the presupposition of EXH's prejacent.

$$
\mathrm{II}_{\text {prs }}((93)):=\left\{\begin{array}{l}
\text { Noah is unaware that O can take } \mathrm{L}[\neg \square[\diamond \mathrm{L}]] \diamond \mathrm{L} \\
\text { Noah is unaware that O can take A }[\neg \square[\diamond \mathrm{A}]] \diamond \mathrm{A}
\end{array}\right\}
$$

Conjoining the presuppositions of those alternatives with the plain presupposition of (93) delivers the presupposed free choice reading we were after: Noah is unaware that Olivia can take Logic or Algebra, and Olivia can take Logic and she can take Algebra, (97).

$$
[\neg \square[\diamond[L \vee A]]] \diamond[L \vee A] \wedge \diamond \mathrm{L} \wedge \diamond A
$$

For completeness, we note that, given our assumptions about the distribution of EXH and the Matrix $K$ operator, the minimal LF for (93) should actually be as follows:

$$
\mathrm{EXH}_{a s r+p r s}^{I E+I I}\left[K_{s}\right. \text { [Noah is unaware that Olivia can take Logic or Algebra]] }
$$

Yet adding the Matrix $K$ operator to the picture does not change the main result above. Consider the presuppositional alternatives to the prejacent of EXH in (98), ignoring again its conjunctive alternative for simplicity:

$$
\begin{aligned}
& \operatorname{ALT}((98)):= \\
& \left\{\begin{array}{l}
{\left[K_{S}[\text { Noah is unaware that O can take L }]\right]\left[K_{S}[\neg \square[\diamond \mathrm{L}]]\right]_{K_{s}[\diamond \mathrm{L}]}} \\
{\left[K_{S}[\text { Noah is unaware that O can take A }]\right]\left[K_{S}[\neg \square[\diamond \mathrm{A}]]\right]_{K_{S}[\diamond \mathrm{A}]}}
\end{array}\right\}
\end{aligned}
$$

In these alternatives, the factive presupposition triggered by unaware projects into $K_{S}$, exactly as in the base sentence. As a result, these alternatives carry the global presuppositions $K_{s}[\diamond \mathrm{L}]$ and $K_{s}[\diamond \mathrm{A}]$, respectively, both of which are stronger than the plain presupposition of EXH's prejacent, i.e., $K_{S}[\diamond[\mathrm{L} \vee \mathrm{A}]]$. Like their non-modalised counterparts above, these presuppositions are not innocently excludable, but they are both innocently includable, and conjoining their presuppositions with the plain presupposition of (98) similarly delivers a presupposed free choice reading:

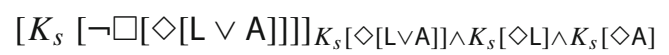


Related cases Our account of presupposed free choice readily extends to more complex cases involving presupposition triggers like discover (see Sect.5.2.1 for discussion). Thus for instance, we predict that a sentence like (101) has a reading on which it asserts that Noah didn't discover that Olivia can take either one of the classes (no free choice), while presupposing that (i) she can choose between the two (free choice) and that (ii) Noah didn't believe that Olivia could take either one (no free choice).

(101) Noah didn't discover that Olivia can take Logic or Algebra.

Similarly, by the same global reasoning as before, we predict that the positive version of (101) in (102) can have a reading on which it asserts that Noah believes that Olivia can take one of the two classes (no free choice), while presupposing that (i) Olivia can choose between the two (free choice) and that (ii) Noah didn't believe that she could take either one before discovering it (no free choice).

(102) Noah discovered that Olivia can take Logic or Algebra.

Interestingly, an anonymous reviewer pointed out to us that the sentence in (102) seems to permit another reading on which free choice is present in the assertion but only affects one part of the presupposition. Specifically, (102) would have a reading asserting that Noah believes that Olivia can choose between the two classes (free choice), while still presupposing that (i) she can choose between the two (free choice), and that (ii) Noah didn't believe that she could take either one before discovering it (no free choice). We believe that this reading is indeed a possible reading of (102). Crucially, we observe that this reading is in fact what our account predicts for (102) if this sentence is parsed as shown in (103), where EXH occurs both at the matrix level and at the level of the complement clause:

(103) $\mathrm{EXH}_{(1)}\left[\right.$ Noah discovered that [ $\mathrm{EXH}_{(2)}$ [Olivia can take Logic or Algebra]]]

On this parse, the free choice inference that Olivia can choose between the two classes is now derived at the embedded level through the working of $\mathrm{EXH}_{(2)}$. As a result, $\mathrm{EXH}_{11}$ 's prejacent asserts that Noah discovered that Olivia can choose between both classes (free choice) and, by projection, presupposes that (i) Olivia can choose between both classes (free choice) and that (ii) Noah didn't believe that she had free choice (free choice under negation). This presupposition doesn't give us yet the desired result, but it can be further strengthened through the working of $\mathrm{EXH}_{(1)}$. In particular, note that $\mathrm{EXH}_{(1)}$ 's prejacent has the following presuppositional alternatives (both of them carry logically independent presuppositions and are Strawson-entailed by the strengthened meaning of $\mathrm{EXH}_{(\mathbb{1})}$ 's prejacent):

(104) a. Noah discovered that Olivia can take Logic. PRS: Olivia can take Logic and Noah didn't believe it (before finding out)

b. Noah discovered that Olivia can take Algebra. PRS: Olivia can take Algebra and Noah didn't believe it (before finding out) 
The presuppositions of those alternatives are not innocently excludable: the falsity of the first part of their presuppositions is inconsistent with the presupposition that Olivia can choose between both classes (free choice) while the falsity of the second part of their presuppositions is inconsistent with the presupposition that Noah didn't believe that she had free choice (free choice under negation). However, the presuppositions of both alternatives are innocently includable and including them give us the additional presupposition we were looking for: before discovering Olivia had free choice, Noah didn't believe that Olivia could take Logic, nor did he believe that she could take Algebra. The resulting reading is thus one that features free choice in one part of the presupposition, but not in the other.

In sum, in extending the notion of innocent inclusion to presuppositional alternatives and presupposed implicatures, the system presented here can derive presupposed free choice rather straightforwardly not only in the basic cases like (93), but also in the more complex ones like (102). In the next subsection, we move to presupposed ignorance and we show that this phenomenon is also accounted for on our approach.

\subsubsection{Presupposed speaker-oriented ignorance}

We now go back to the novel oddity effects in (50), which we observed to be parallel to those arising in their non-embedded, non-presuppositional variants in (51).
a. \#Noah is unaware that I have two or more children.
b. \#Sue didn't realize that my wife is from France or Italy.
c. \#Mary was sorry that Sue had lunch with Noah or me yesterday.
a. \#I have two or more children.
b. \#My wife is from France or Italy.
c. \#Sue had lunch with Noah or me yesterday.

In line with the previous literature, we attributed the oddity of the sentences in (51) to the obligatory presence of speaker-oriented ignorance inferences about the disjuncts. Specifically, we argued that a sentence like (51-b) is odd because it has an LF along the lines of (105), which conveys that the speaker believes that his wife is from France or Italy but that he is ignorant as to which of these two countries she is from (an information that is generally odd for one not to have about a close relative).

$\left[\mathrm{EXH}_{\mathcal{R}}\left[K_{s}[\mathrm{my}\right.\right.$ wife is from France or Italy $\left.]\right]$

a. $\quad \mathrm{IE}_{a s r}=\left\{\left[K_{s}\right.\right.$ [FRANCE AND ITALY $],\left[K_{s}\right.$ [FRANCE $],\left[K_{s}[\right.$ ITALY $\left.\left.]\right]\right\}$

b. $\sim K_{S}[$ FRANCE OR ITALY $] \wedge I_{S}[$ FRANCE $] \wedge I_{S}[$ ITALY $]$

On our approach, this line of explanation straightforwardly extends to the presuppositional cases in (50). To illustrate, consider the presuppositional variant of (51-b) in (50-b) which, in our view, has the following minimal parse:

$$
\left[\mathrm { EXH } _ { \mathcal { R } } \left[K_{s}\right.\right. \text { [Sue didn't realize that my wife is from France or Italy]]] }
$$


The non-weaker alternatives to EXH's prejacent are shown in (107): all these alternatives are presuppositional alternatives and their presuppositions are innocently excludable.

$$
\mathrm{IE}^{p r s}=\left\{\begin{array}{ll}
{\left[K_{S}[\text { Sue didn't realize that } \mathrm{F} \text { and } \mathrm{I}]\right]\left[K_{S}[\neg \square[\mathrm{F} \wedge \mathrm{I}]]\right]_{K_{s}[\mathrm{~F} \wedge \mathrm{I}]}} \\
{\left[K_{S}[\text { Sue didn't realize that } \mathrm{F}]\right]} & {\left[K_{S}[\neg \square[\mathrm{F}]]\right]_{K_{S}[\mathrm{~F}]}} \\
{\left[K_{S}[\text { Sue didn't realize that I }]\right]} & {\left[K_{S}[\neg \square[\mathrm{I}]]\right]_{K_{s}[\mathrm{I}]}}
\end{array}\right\}
$$

The outcome of the exhaustification process is thus as shown in (108): it is presupposed that the speaker believes that his wife is from France or from Italy but doesn't know which of these two countries she is from. As before, our assumptions about the calculation of relevance for disjunctive sentences make it so that, since the disjunctive presupposition of the base sentence has to be relevant for this sentence to be acceptable, its presuppositional alternatives presupposing the independent disjuncts must also be relevant and, consequently, cannot be pruned from the domain of EXH, which makes the corresponding ignorance inferences obligatory (see Sect.5.1.3 and Marty and Romoli 2020 for discussion). In other words, our proposal derives presupposed ignorance in a completely analogous way as assertive ignorance, and we argue that this is the source of the oddness of the sentences in (50).

$$
\left[K_{S}[\neg \square[\mathrm{F} \vee \mathrm{I}]]\right]_{K_{s}[\mathrm{~F} \vee \mathrm{l}] \wedge I_{s}[\mathrm{~F}] \wedge I_{s}[1]}
$$

For completeness, we note the infelicity of these sentences cannot be rescued by adding an extra layer of exhaustification below $K$ for such an addition can only strengthen the outcome in (108). For instance, our system allows for (50-b) the following richer parse:

\section{$\mathrm{EXH}_{(1)}\left[K_{S}\left[\mathrm{EXH}_{(2)}[\right.\right.$ Sue didn't realize that my wife is from France or Italy] $\left.]\right]$}

The non-weaker alternatives to $\mathrm{EXH}_{2}$ 's prejacent are shown in (110-a): all these alternatives are presuppositional alternatives but, of these alternatives, only the one carrying a conjunctive presupposition, namely $[\mathrm{F} \wedge \mathrm{I}]$, is innocently excludable, (110-b). The outcome of this first exhaustification process is thus as shown in (110-c).

$$
\begin{aligned}
& \text { a. } \operatorname{ALT}_{\text {prs }}(2)=\left\{\begin{array}{ll}
{[\text { Sue didn't realize that } \mathrm{F} \text { and } \mathrm{I}][\neg \square[\mathrm{F} \wedge \mathrm{I}]]_{[\mathrm{F} \wedge \mathrm{I}]}} \\
{[\text { Sue didn't realize that } \mathrm{F}]} & {[\neg \square[\mathrm{F}]]_{[\mathrm{F}]}} \\
{[\text { Sue didn't realize that I] }} & {[\neg \square[\mathrm{I}]]_{[\mathrm{I}]}}
\end{array}\right\} \\
& \text { b. } \quad \mathrm{IE}_{\text {prs }}(\text { (2) })=\{[\text { Sue didn't realize that } \mathrm{F} \text { and } \mathrm{I}]\} \\
& \text { c. Outcome: }[\neg \square[\mathrm{F} \vee \mathrm{I}]]_{[\mathrm{F} \vee \mathrm{I}] \wedge \neg[\mathrm{F} \wedge \mathrm{I}]}
\end{aligned}
$$

Consider now the structural alternatives to $\mathrm{EXH}_{(1)}$ 's prejacent in (111), each of which is logically non-weaker than $\mathrm{EXH}_{(\mathbb{1})}$ 's prejacent and thus a potential candidate for exclusion (for simplicity, we are leaving out the conjunctive alternatives, which can be safely ignored). 


$$
\begin{aligned}
& \operatorname{ALT}(1)= \\
& \left\{\begin{array}{ll}
{\left[K_{S}\left[\mathrm{EXH}_{(2)}[\text { Sue didn't realize that F }]\right]\right]\left[K_{S}[\neg \square[\mathrm{F}] \wedge \square[\mathrm{I}]]\right]_{K_{s}[\mathrm{~F}] \wedge K_{S}[\mathrm{I}]}} \\
{\left[K_{S}\left[\mathrm{EXH}_{(2)}[\text { Sue didn't realize that I] }]\right]\right.} & {\left[K_{s}[\neg \square[\mathrm{II} \wedge \square[\mathrm{F}]]]_{K_{S}[\mathrm{I}] \wedge K_{s}[\mathrm{~F}]}\right.} \\
{\left[K_{S}[\text { Sue didn't realize that F }]\right]} & {\left[K_{S}[\neg \square[\mathrm{F}]]\right]_{K_{S}[F]}} \\
{\left[K_{S}[\text { Sue didn't realize that I] }]\right.} & {\left[K_{S}[\neg \square[\mathrm{I}]]\right]_{K_{S}[I]}}
\end{array}\right\}
\end{aligned}
$$

The first two alternatives in (111), those with $\mathrm{EXH}_{(2)}$, are assertive alternatives: they both carry stronger presuppositions, but they are not Strawson-entailed by EXH $\mathrm{E}_{1}$ 's prejacent. By contrast, the last two alternatives, those without $\mathrm{EXH}_{(2)}$, are presuppositional alternatives: they carry stronger presuppositions and they are Strawson-entailed by $\mathrm{EXH}_{(1)}$ 's prejacent. The sets of excludable presuppositional and assertive alternatives to $\mathrm{EXH}_{1}$ 's prejacent are thus as shown in (112-a) and (112-b), respectively.

$$
\begin{aligned}
& \text { a. } \quad \mathrm{E}_{\text {prs }}(1)=\left\{\begin{array}{l}
{\left[K_{S}[\text { Sue didn't realize that } \mathrm{F}]\right]\left[K_{S}[\neg \square[\mathrm{F}]]\right]_{K_{S}[F]}} \\
{\left[K _ { S } \left[\text { Sue didn't realize that I] }\left[K_{S}[\neg \square[\mathrm{I}]]\right]_{K_{S}[I]}\right.\right.}
\end{array}\right\} \\
& \text { b. } \mathrm{E}_{a s r}(1)= \\
& \left\{\begin{array}{l}
{\left[K_{S}\left[\mathrm{EXH}_{(2)}[\text { Sue didn't realize that F] }]\right]\left[K_{S}[\neg \square[\mathrm{F}] \wedge \square[\mathrm{I}]]\right]_{K_{S}[\mathrm{~F}] \wedge K_{S}[\mathrm{I}]}\right.} \\
{\left[K _ { S } \left[\mathrm { EXH } _ { ( 2 ) } \left[\text { Sue didn't realize that I]]] }\left[K_{S}[\neg \square[\mathrm{I}] \wedge \square[\mathrm{F}]]\right]_{K_{S}[\mathrm{I}] \wedge K_{S}[\mathrm{~F}]}\right.\right.\right.}
\end{array}\right\}
\end{aligned}
$$

It is easy to see that the presuppositions of the presuppositional alternatives in (112-a) can be both consistently negated without contradicting $\mathrm{EXH}_{(1)}$ 's prejacent. Thus, the alternatives in (112-a) are both $\mathrm{IE}_{\text {prs }}$ alternatives, and excluding their presuppositions give rise to the same ignorance inferences as before. On the other hand, neither of the assertive alternatives in (112-b) is innocently excludable. Indeed, on our approach, the set of $\mathrm{IE}_{a s r}$ alternatives corresponds to the intersection of all maximal sets of assertive alternatives that can be negated consistently with the prejacent and the negation of the presupposition of all $\mathrm{IE}_{\text {prs }}$ alternatives. In the present case, the assertive alternatives in (112-b) carry the conjunctive presupposition $K_{S}[\mathrm{~F}] \wedge K_{S}[\mathrm{I}]$ and this presupposition is inconsistent with the presupposed implicatures derived from the $\mathrm{IE}_{\text {prs }}$ alternatives, i.e., $\neg K_{S}[\mathrm{~F}]$ and $\neg K_{S}[\mathrm{l}]$. Hence, $\mathrm{EXH}_{(1)}$ 's prejacent doesn't give rise to any assertive implicature. We end up for (109) with the final representation below. As the reader can verify, this representation preserves the outcome of the more minimal parse while adding the presupposed implicature that the speaker doesn't believe that his wife is both from France and from Italy.

(109) $\operatorname{EXH}_{(1)}\left[K_{S}\left[\mathrm{EXH}_{(2)}[\right.\right.$ Sue didn't realize that my wife is from France or Italy $\left.]\right]$

$$
\begin{array}{lll}
\text { a. } & \text { PRS: } & K_{s}[[\mathrm{~F} \vee I] \wedge \neg[\mathrm{F} \wedge I]] \wedge I_{S}[F] \wedge I_{S}[I] \\
\text { b. } & \text { ASR: } & K_{S}[\neg \square[\mathrm{F} \vee I]]
\end{array}
$$

In sum, the system presented here provides a unified analysis of presupposed implicatures, including presupposed free choice and presupposed speaker's ignorance. More generally, it accounts for the parallelism between implicatures arising in the assertion and those arising only in the presupposition. Before concluding the paper, we briefly discuss in the next section some alternative directions one might want to explore in response to our puzzles. 


\section{Other directions}

Having presented the challenges at stake and explained how our proposal addresses them, we turn to two alternative directions and identify the issues which we believe they would need to overcome. The first direction is based on a recent generalisation by Anvari (2018, 2019), called Logical Integrity, which aims at capturing a broad class of unacceptable sentences. As we will see, this approach has troubles with our two main challenges, presupposed free choice and presupposed ignorance. The second direction is to consider an approach to free choice and ignorance radically different from the implicature-based approach pursued in this paper. As we discuss, this approach can address the challenge raised by presupposed free choice. Yet various issues carry over from the assertion to the presupposition level, and this direction cannot extend to the presupposed ignorance cases.

\subsection{Logical integrity}

Logical integrity (LI henceforth) is a generalisation from Anvari (2018, 2019), the aim of which is to capture the unacceptability of a variety of sentences, part of which are the ones that Spector and Sudo's (2017) PIP was originally designed to capture. The gist of this generalisation is that a sentence $\phi$ is deemed infelicitous if it has an alternative $\psi$ that is logically non-weaker, yet contextually entailed by $\phi$. In sum, LI forces the logical relation between a sentence and its alternatives to be preserved once contextual information is considered, hence the name of 'logical integrity'. We will consider the formulation of this principle in (113) and assume that a sentence is odd if any part of it violates (113). ${ }^{42}$

(113) Logical Integrity (from Anvari 2019: (5))

A sentence $\phi$ must not be uttered in context $c$ if it has an alternative $\psi$ such that (i) $\phi$ contextually entails $\psi$ in $c$, but (ii) $\phi$ does not logically entail $\psi$.

Consider first how LI fares with respect to presupposed free choice, (114).

(114) Noah is unaware that Olivia can take Logic or Algebra.

$\sim$ Olivia can take Logic and she can take Algebra

For these cases, LI encounters two issues that are similar to those previously encountered by Spector and Sudo's (2017) account. First, in a context in which it is common knowledge that Olivia has free choice between Logic and Algebra, (114) is predicted by LI to be odd since the following alternatives are contextually but not logically entailed by (114):

a. Noah is unaware that Olivia can take Logic.

b. Noah is unaware that Olivia can take Algebra.

\footnotetext{
42 This is not the final version of the principle, which is associated with an additional 'projection principle' for local applications, but it is enough for our purposes; see Anvari (2019) for discussion.
} 
Second, LI cannot derive by itself the presupposed free choice reading of interest: in a run-of-the-mill context, reasoning with LI over (114) can at best give rise to the inferences that it's not common knowledge that Olivia can take Logic and that she can take Algebra. Of course, deriving presupposed free choice independently, e.g., by amending Spector and Sudo's (2017) EXH operator, would solve both these issues at once. As we have established in Sect. 4.1, however, this move comes at the cost of losing Spector and Sudo's (2017) of other cases we discussed, e.g., the asymmetry in (4).

Let us turn now to the presupposed ignorance cases and consider first the case discussed in Spector and Sudo's (2017) and repeated below.

CONTEXT: The interlocutors know that Olivia only took Logic.

\#Noah is unaware that Olivia took Logic or Algebra.

As Anvari (2018, 2019) discusses, LI captures the infelicity of this sentence since this sentence contextually entails one of its logically non-weaker alternatives, namely (116).

(116) Noah is unaware that Olivia took Logic.

Despite this good result, the presupposed ignorance challenge we presented in this paper extends to Anvari's proposal. Just like the PIP, LI does not account for the infelicity effects in (50): as long as it is not common knowledge how many children the speaker has, the offending alternatives to an utterance of (50-a) are not contextually entailed by that utterance, and therefore (50-a) and similar examples are not predicted to be infelicitous.
a. \#Noah is unaware that I have two or more children.
b. \#Sue did not realize that my wife is from France or Italy.
c. \#Mary was sorry that Sue had lunch with Noah or me yesterday.

In sum, the Logical Integrity approach does not, at least in its current form, offer a solution to our main challenges. In the next subsection, we turn to non-implicature approaches to free choice and ignorance.

\subsection{Non-implicature approaches to free choice and ignorance}

One common response to Fox's (2007) original argument is to argue that free choice is not an implicature to begin with. And indeed, the status of free choice is still controversial in the current literature, with some arguments in favour and others against an implicature approach (see, a.o., Bar-Lev 2018; Goldstein 2019; Franke 2011; Aloni 2018; Santorio and Romoli 2017; Romoli and Santorio 2019 for discussion). Without going into details of the different non-implicature accounts, we show in the following that a non-implicature approach to free choice can indeed be extended to our presupposed free choice cases. There is still of course the partly independent question as to which of these two approaches to free choice ultimately handles free choice best. We will not be able to address this more general issue here, but we will show that some of 
the problems of the non-implicature approach arising at the assertion level carry over to the presupposition level.

A variety of non-implicature approaches to free choice have recently been defended (a.o., Aloni 2018; Willer 2017; Goldstein 2019). For concreteness, we will focus here on the account in Goldstein (2019) (see Rothschild and Yablo 2018 for a similar proposal). Most of the considerations we make below, however, apply to other non-implicature accounts. The gist of Goldstein's (2019) account relies on two main assumptions. First, it assumes that a sentence like (117), repeated from above, directly asserts FREE CHOICE, as schematised in (117-a). Second, it assumes that the modal introduces a homogeneity presupposition requiring that either both disjuncts are possible or neither of them is, $(117-b){ }^{43}$

(117) Olivia can take Logic or Algebra.

a. $\diamond(\mathrm{L} \vee \mathrm{A})=\diamond \mathrm{L} \wedge \diamond \mathrm{A}$

b. $\diamond \mathrm{L} \leftrightarrow \diamond \mathrm{A}$

FREE CHOICE

HOMOGENEITY PRESUPPOSITION

In the positive case, the asserted meaning in (117-a) directly accounts for free choice, while the homogeneity inference plays no role, i.e., it is entailed by (117-a). Under negation, the asserted meaning becomes the negation of FREE CHOICE:

$$
\neg(\diamond(\mathrm{L} \vee \mathrm{A}))=\neg \diamond \mathrm{L} \vee \neg \diamond \mathrm{A}
$$

NEGATED FREE CHOICE

In combination with the homogeneity presupposition in (117-b), which projects through negation, (118) gives rise to the desired DOUBLE PROHIBITION reading. In sum, the assertion in (117-a) together with the homogeneity presupposition in (117-b) capture the attested pattern in the basic case of free choice and double prohibition.

$$
\begin{aligned}
& (\neg \diamond \mathrm{L} \vee \neg \diamond \mathrm{A}) \wedge(\diamond \mathrm{L} \leftrightarrow \diamond \mathrm{A}) \\
& =\neg \diamond \mathrm{L} \wedge \neg \diamond \mathrm{A}
\end{aligned}
$$

DOUBLE PROHIBITION

Consider now how this approach to free choice can account for our presupposed free choice cases. We will focus here on the case in (6), repeated below:

(6) Noah is unaware that Olivia can take Logic or Algebra.

This sentence can be schematically represented as in (120) (as before, we use ' $\square$ ' to represent Noah's belief worlds in the evaluation world).

$$
[\neg \square[\diamond(L \vee A)]] \diamond(L \vee A)
$$

Crucially, on this account, the meaning of the embedded clause, $\diamond(L \vee A)$, is now directly encoding free choice, $\diamond \mathrm{L} \wedge \diamond \mathrm{A}$. In addition, (120) presupposes the truth of its embedded clause, which directly accounts for the free choice inference observed in the presupposition. Finally, we assume that the homogeneity presupposition projects universally through unaware, as indicated in (121) in the subscript. ${ }^{44}$

\footnotetext{
43 We set aside here how this result is obtained compositionally; see Goldstein (2019) for discussion.

44 A theory of how the homogeneity presupposition is to project in complex sentences is a central feature of this approach. The assumption we make here regarding universal projection through attitude predicates
} 


$$
[\neg \square[\diamond(L \vee A)]]_{\diamond(L \vee A)}=[\neg \square[\diamond(L \vee A)]]_{[\diamond(L) \wedge \diamond(A)] \wedge \square[\diamond L \leftrightarrow \diamond A]}
$$

The representation resulting from the combination of these ingredients gives rise to the intuitively correct reading, (122): it asserts that it is possible for Noah that Olivia can't take either of the two classes, i.e. DOUBLE PROHIBITION is possible according to Noah, and presupposes at the same time that she can take one and that she can take the other, i.e. she actually has FREE CHOICE between the two. ${ }^{45}$

$$
\begin{array}{ll}
\text { a. } & \diamond[\neg \diamond \mathrm{L} \wedge \neg \diamond \mathrm{A}] \\
\text { b. } \diamond \mathrm{L} \wedge \diamond \mathrm{A}
\end{array}
$$

ASSERTION PRESUPPOSITION

This non-implicature approach to free choice, when integrated with either the PIP by Spector and Sudo (2017) or LI by Anvari (2019), correctly predicts that, under the intended presupposed free choice reading, a sentence like (6) should be felicitous in the previously problematic contexts since its presupposition (i.e., that Olivia can choose between Logic and Algebra) is now stronger than the presupposition of any of its alternatives.

We note, however, that some of the issues already identified in the literature for this non-implicature approach to free choice reproduce at the presupposition level (see Romoli and Santorio 2019 for discussion). We briefly mention two of them here. The first one pertains to the assumption (at least in Goldstein's implementation) that double prohibition is derived through a combination of the negated literal meaning and the homogeneity presupposition. To illustrate, consider (123) for instance:

\section{PRESUPPOSED DOUBLE PROHIBITION}

Noah is unaware that Olivia cannot take Algebra or Logic.

$\sim$ Olivia cannot take Algebra and she cannot take Logic

Intuitively, (123) conveys that Olivia cannot take either of the two classes and that Noah believes that she can take at least one of the two. This reading is correctly derived on Goldstein's approach given the homogeneity presupposition associated with the embedded clause: the factive presupposition triggered by unaware, (124-a), together with its homogeneity presupposition, (124-b), gives rise to double prohibition, (124-c).

$$
\begin{aligned}
& \text { a. } \neg(\diamond(\mathrm{L} \vee \mathrm{A}))=\neg \diamond \mathrm{L} \vee \neg \diamond \mathrm{A} \\
& \text { b. } \diamond \mathrm{L} \leftrightarrow \diamond \mathrm{A} \\
& \text { c. } \neg \diamond \mathrm{L} \wedge \neg \diamond \mathrm{A}
\end{aligned}
$$

FACTIVITY

HOMOGENEITY DOUBLE PROHIBITION

The problem, however, is that this reading appears to remain available in contexts where the relevant homogeneity presupposition cannot be satisfied. Consider for instance the following context (cf. Romoli and Santorio 2019 for a similar argument):

Footnote 44 continued

is based on the universal projection predictions for universal quantifiers; see Križ (2015) and Goldstein (2019) for discussion.

45 Cases involving factive adjectives and emotive factives can be derived in a similar way, though they require discussion of different assumptions about their meaning components and presupposition projection, which we cannot discuss here for reasons of space; see a.o. von Fintel (1999) and Heim (1992). 
(125) CONTEXT: As a rule, each student can take any number of courses $(0,1,2$, 3 , etc.) and, crucially, no student has to take any two classes at once.

Noah is unaware that Olivia cannot take Logic or Algebra.

Intuitively, the sentence at hand still gives rise to double prohibition, i.e., Olivia cannot take Logic and she cannot take Algebra. In this case, however, it is unclear how to derive this inference on Goldstein's (2019) approach since the homogeneity inference that Olivia can take Logic if and only if she can take Algebra conflicts with the context. In sum, the problem of presupposed free choice reproduces with presupposed double prohibition.

The second issue has to do with the fact that the non-implicature account above does not derive the so-called 'negative free choice' inferences illustrated below in (126) (Fox 2007; Chemla 2009b; see also Ciardelli et al. 2018; Romoli and Santorio 2019 for discussion).

\section{NEGATIVE FREE CHOICE}

Olivia is not required to take Logic and Algebra.

$\sim$ Olivia is not required to take Logic and she is not required to take Algebra

We further observe here that the very same inference is found at the presupposition level, thus extending the problem above to 'presupposed negative free choice' inferences.

PRESUPPOSED NEGATIVE FREE CHOICE

Noah is unaware that Olivia is not required to take Logic and Algebra.

$\sim$ Olivia is not required to take Logic and she is not required to take Algebra

Finally, we note that it remains an open question whether ignorance inferences can receive a non-implicature account in the same spirit and, if so, whether such an account would adequately extend to presupposed ignorance. One could hypothesise for instance that a disjunctive sentence like (128) literally presupposes that the speaker is ignorant as to whether Olivia took logic and as to whether she took Algebra.

Olivia took Logic or Algebra.

a. $(\mathrm{L} \vee \mathrm{A})$

ASSERTION

b. $I_{S}(\mathrm{~L}) \wedge I_{S}(\mathrm{~A})$

IGNORANCE PRESUPPOSITION

Beside its stipulative nature, this hypothesis would fail to address the presupposed ignorance challenge: for a sentence like (129), it would only predict presuppositions of the form ' $\square\left(I_{S}(\mathrm{~L}) \wedge I_{S}(\mathrm{~A})\right)$ ', where the ignorance presupposition of the embedded disjunction has universally projected into the attitude predicate. The presupposition could be thus paraphrased as follows: according to Noah, the speaker is ignorant as to whether Olivia took Logic or Algebra. This is obviously an unwarranted result.

(129) Noah is unaware that Olivia took Logic or Algebra.
a. $\neg \square(\mathrm{L} \vee \mathrm{A})$
ASSERTION
b. $\square\left(I_{S}(\mathrm{~L}) \wedge I_{S}(\mathrm{~A})\right)$
IGNORANCE PRESUPPOSITION 
More dramatically perhaps, this hypothesis would make incorrect predictions for basic negated cases like (130): it would predict (130) to presuppose that it is possible, according to the speaker, that Olivia took Logic and Algebra, in contradiction with the asserted content that she didn't take either one. ${ }^{46}$

(130) Olivia didn't take Logic or Algebra.

a. $\neg(\mathrm{L} \vee \mathrm{A})=\neg \mathrm{L} \wedge \neg \mathrm{A}$

ASSERTION

b. $I_{S}(\mathrm{~L}) \wedge I_{S}(\mathrm{~A})$

IGNORANCE PRESUPPOSITION

In sum, while the non-implicature approach to free choice can account for the presupposed free choice challenge, there are a variety of issues with this approach which carry over from the assertion to the presupposition level. Finally, it remains unclear whether such a non-implicature account could extend to (presupposed) ignorance inferences.

\section{Conclusion}

Previous work have investigated cases in which genuine implicatures appear to be computed only in the presupposition of a sentence. Some researchers have taken these cases to be evidence that implicatures can arise at the presupposition level, and proposed a unified grammatical account of assertion-based and presupposition-based implicatures (Gajewski and Sharvit 2012; Magri 2009; Marty 2017). Spector and Sudo (2017) recently challenged this unified approach based on certain asymmetries between positive and negative factives, and the observation that ignorance inferences also arise at the presupposition level. Spector and Sudo (2017) proposed instead a hybrid account relying on two distinct scalar strengthening mechanisms: a grammatical theory of implicatures for deriving implicatures in the assertion, and an independent pragmatic principle for deriving implicatures in the presupposition.

Our goal in this paper was to contribute to this ongoing debate by putting forward two novel empirical observations. First, we have observed that FREE CHOICE inferences can also arise at the presupposition level, and sometimes only at the presupposition level. Thus for instance, a sentence like (6), repeated below, has a reading conveying that Noah doesn't believe that Olivia can take either class, while suggesting that she has free choice between the two. Hence, in parallel to the other cases of presupposed implicatures, the FREE CHOICE inference in (6) appears in the presupposition but not in the assertion.

(6) Noah is unaware that Olivia can take Logic or Algebra.

a. ASSERTION

Noah doesn't believe that Olivia can take either one

b. PRESUPPOSITION

Olivia can take Logic or Algebra

\footnotetext{
46 Note that locally accommodating the ignorance presupposition under negation would not really help here as it would weaken the plain meaning of (130). In particular, it would make (130) true if, according to the speaker, it is possible that Olivia took Logic.
} 


\section{c. PRESUPPOSED FREE CHOICE \\ $\sim$ Olivia can take Logic and she can take Algebra}

Second, we have observed that presupposition-based ignorance inferences are stronger than discussed in Spector and Sudo (2017), and in fact of similar strength as the wellknown assertion-based ones. Thus for instance, an utterance of (131-a) doesn't merely convey that it is not common knowledge whether Olivia has two or more children, but rather that the speaker is ignorant as to how many children Olivia has. While the speaker-orientation of these ignorance inferences may be harder to detect in cases like (131-a), it becomes obvious in cases like (131-b): this utterance is perceived as infelicitous, even in a context in which it is not common knowledge how many children the speaker actually has.

(131) a. Noah is unaware that Olivia has two or more children.

b. \#Noah is unaware that I have two or more children.

We showed that both phenomena are problematic for Spector and Sudo (2017). First, we showed that deriving the presupposed free choice reading of (6) is challenging in at least two ways: allowing this inference to be derived from the working of their exhaustivity operator leads to over-generation issues, and deriving this inference with the pragmatic side of their system is challenging for the same reasons as deriving regular free-choice inferences is challenging for a pragmatic approach to assertionbased implicatures. In that respect, our dialectic closely followed that of Fox (2007): we have argued against a pragmatic approach to presupposition-based implicatures on the ground that it is not able to account for presupposed free choice. In addition, we showed that the kind of presupposed ignorance inferences that can be derived in Spector and Sudo's (2017) system are too weak to account for cases like (131).

More generally, these novel data have unveiled a systematic parallelism between the assertion and presupposition levels in terms of EXCLUSIVITY (9), FREE CHOICE (10), and IGNORANCE inferences (11). We have argued that a grammatical theory of implicatures where meaning strengthening operates in the same way at the assertion and presupposition levels (Gajewski and Sharvit 2012; Magri 2009; Marty 2017), combined with a grammatical account of ignorance inferences à la Meyer (2013), can account for this parallelism and provide a unified analysis of those inferences.

\section{Exclusivity and Presupposed Exclusivity}

a. Olivia took Logic or Algebra. $\sim$ Olivia didn't take both Logic and Algebra

b. Noah is unaware that Olivia took Logic or Algebra. $\leadsto$ Olivia didn't take both Logic and Algebra

\section{Free Choice and Presupposed Free Choice}

a. Olivia is allowed to take Logic or Algebra. $\sim$ Olivia can take Logic and she can take Algebra

b. Noah is unaware that Olivia is allowed to take Logic or Algebra. $\sim$ Olivia can take Logic and she can take Algebra 


\section{(11) Ignorance and Presupposed Ignorance}

a. Olivia took Logic or Algebra.

$\sim$ The speaker doesn't know which of the two classes Olivia took

b. Noah is unaware that Olivia took Logic or Algebra.

$\sim$ The speaker doesn't know which of the two classes Olivia took

Finally, in the last part of this paper, we have discussed two alternatives directions, the first one based on the recent account by Anvari $(2018,2019)$ and the other based on non-implicature accounts of free choice and ignorance. We have presented the gist of these accounts and pointed out the issues they would have to overcome in order to achieve the same empirical coverage as the one offered by our proposal.

Before closing this paper, we would like to emphasise three more points, which we think can help contextualise our contribution in the general discussion of the interactions between presuppositions, free choice and implicatures. First, the parallelism between assertion and presupposition levels that we found appears to extend to other inferences which have been claimed to be implicatures. For instance, we observe that the multiplicity inference associated with plural sentences like (132), which has received implicature-based accounts (see Spector 2007; Zweig 2009; Ivlieva 2013; Mayr 2015 among others), reproduce at the presupposition level, as shown in (133).

(132) There are students around.

$\sim$ There is more than one student around

MULTIPLICITY

(133) Noah didn't realise that there are students around.

a. ASSERTION

Noah doesn't believe that there is any student around

b. PRESUPPOSITION

There is one or more students around

c. PRESUPPOSED MULTIPLICITY

$\sim$ There is more than one student around

Similar data can be reproduced for other inferences which have been treated as scalar implicatures like the homogeneity effects associated with plural definites (Magri 2014; Bar-Lev 2018) or the inference of neg-raising predicates (Romoli 2013). We take these additional parallels as further evidence that a unified analysis like the one offered in this paper is desirable, but leave an exploration of how such an approach would extend to these cases for further research.

Second, it is useful to clarify how our presupposed free choice cases relate to but also differ from the cases recently discussed in Romoli and Santorio (2019) and in which a free choice inference appears to filter a presupposition. Some of these cases are conditional sentences like (134), which involve a presuppositional phrase in the consequent, the presupposition of which (i.e., Olivia can go study in Japan) appears to be filtered by the free choice inference of the antecedent (i.e., Olivia can go study in Tokyo and can go study in Boston). 
(134) If Olivia can go study in Tokyo or Boston, she is the first in our school who can go study in Japan.

ұ Olivia can go study in Japan

Our case, by contrast, has to do with free choice inferences arising at the presupposition level, independently from the assertion level. Both cases are thus concerned with the interaction between free choice and presuppositions, but in different ways: their cases evidence the ability of free choice to filter presuppositions, while ours its potential to enrich presuppositions. We take both cases to show, in their own ways, that looking at free choice in the context of the interaction between implicatures and presuppositions is a fruitful ground to further improve our understanding of such interactions and of free choice itself.

Finally, we conclude by mentioning some remaining puzzles for non-MP accounts of presupposed implicatures. Marty and Romoli (2020) discuss examples like (135) and (136) and show that these cases raise an issue for all approaches discussed in this paper (i.e., Spector and Sudo 2017; Anvari 2019, as well as the implicature account we put forward).

(135) CONTEXT: All of the students used to smoke and possibly still do. If some of the students stopped smoking, Jane will be happy. PRESUPPOSITION: some of the students used to smoke

(136) CONTEXT: Some students met with both Danny and Irene. The students who met with Danny or Irene understood the puzzle. PRESUPPOSITION: there are students who met with Danny or Irene

Let us briefly illustrate the problem by focusing on (135). First, we assume that the plain presupposition of (135) is not universal (Chemla 2009a, among many others) and, second, we observe that the stronger presupposition of the all-alternative to (135) in (137) is satisfied in the context by assumption.

(137) If all of my students stopped smoking, Jane will be happy.

PRESUPPOSITION: all of the students used to smoke (and possibly still do)

Spector and Sudo's (2017) PIP incorrectly predicts (135) to be infelicitous in the given context; we also note that global exhaustification would be vacuous here and that local exhaustification within the antecedent would not give rise to the intended meaning. Anvari's (2018) LI also incorrectly predicts (135) to be infelicitous here since (135) does not entail (137) logically, but it does so contextually. Finally, in the system we defended, the fact that the presupposition of (137) is satisfied by assumption makes it relevant and, therefore, the (conflicting) presuppositional implicature associated with this presupposition should be obligatory. As a result, we also incorrectly predict (135) to be infelicitous. Similar observations hold for (136), given the alternative in (138). In other words, accounting for the felicity of (135) and (136) remains an open challenge for each of the three accounts. 
(138) The students who met with Danny and Irene understood the puzzle. PRESUPPOSITION: there are students who met with Danny and Irene

We hope that future work on presupposed implicatures will take up on these remaining challenges in offering a suitable account of the felicity of these recalcitrant examples. We do think, however, that such an account needs to retain the unified approach to assertion-based and presupposition-based implicatures that we defended here.

Open Access This article is licensed under a Creative Commons Attribution 4.0 International License, which permits use, sharing, adaptation, distribution and reproduction in any medium or format, as long as you give appropriate credit to the original author(s) and the source, provide a link to the Creative Commons licence, and indicate if changes were made. The images or other third party material in this article are included in the article's Creative Commons licence, unless indicated otherwise in a credit line to the material. If material is not included in the article's Creative Commons licence and your intended use is not permitted by statutory regulation or exceeds the permitted use, you will need to obtain permission directly from the copyright holder. To view a copy of this licence, visit http://creativecommons.org/licenses/by/4.0/.

\section{References}

Aloni, M. (2018). FC disjunction in state-based semantics. Unpublished ms., University of Amsterdam.

Alonso-Ovalle, L., \& Menéndez-Benito, P. (2010). Modal indefinites. Natural Language Semantics, 18(1), $1-31$.

Alxatib, S. (2014). Free choice disjunctions under only. Proceedings of NELS, 44, 15-28.

Anvari, A. (2018). Logical integrity. Semantics and Linguistic Theory, 28, 711-726.

Anvari, A. (2019). Logical Integrity: From Maximize Presupposition! to Mismatching Implicatures. Unpublished ms., ENS.

Bar-Lev, M. (2018). Free choice, homogeneity and innocent inclusion. The Hebrew University of Jerusalem dissertation.

Bar-Lev, M., \& Fox, D. (2020). Free choice, simplification, and innocent inclusion. Natural Language Semantics, 28, 175-223.

Beaver, D., \& Clark, B. Z. (2009). Sense and sensitivity. How focus determines meaning. Oxford: Oxford University Press.

Bennett, P. A. (1979). On Universal 23. Linguistic Inquiry, 10(3), 510-511.

Breheny, R., Klinedinst, N., Romoli, J., \& Sudo, Y. (2017). The symmetry problem: Current theories and prospects. Natural Language Semantics, 26(2), 85-110.

Buccola, B., \& Haida, A. (2019). Obligatory irrelevance and the computation of ignorance inferences. Journal of Semantics, 36(4), 583-616.

Chemla, E. (2008). An epistemic step for anti-presuppositions. Journal of Semantics, 25(2), 141-173.

Chemla, E. (2009a). Presuppositions of quantified sentences: Experimental data. Natural Language Semantics, 17(4), 299-340.

Chemla, E. (2009b). Universal implicatures and free choice effects: Experimental data. Semantics \& Pragmatics, 2(2), 1-33. https://doi.org/10.3765/sp.2.2.

Chemla, E. (2010). Similarity: Towards a unified account of scalar implicatures, free choice permission and presupposition projection. Unpublished ms., ENS.

Chierchia, G. (2004). Scalar implicatures, polarity phenomena, and the syntax/pragmatics interface. In A. Belletti (Ed.), Structures and beyond: The cartography of syntactic structures (Vol. 3, pp. 39-103). Oxford: Oxford University Press.

Chierchia, G. (2006). Broaden your views: Implicatures of domain widening and the "logicality" of language. Linguistic Inquiry, 37(4), 535-590.

Chierchia, G. (2013). Logic in grammar: Polarity, free choice, and intervention. Oxford: Oxford University Press.

Chierchia, G., Fox, D., \& Spector, B. (2012). The grammatical view of scalar implicatures and the relationship between semantics and pragmatics. In C. Maienborn, K. von Heusinger, \& P. Portner (Eds.), 
Semantics: An international handbook of natural language meaning (Vol. 3, pp. 2297-2332). Berlin: Mouton de Gruyter.

Ciardelli, I., Linmin, Z., \& Champollion, L. (2018). Two switches in the theory of counterfactuals: A study of truth conditionality and minimal change. Linguistics and Philosophy, 41(6), 577-621.

Cohen, L. J. (1971). Some remarks on Grice's views about the logical particles of natural language. In Y. Bar-Hillel (Ed.), Pragmatics of natural languages (pp. 50-68). Dordrecht: Springer.

Elliott, P., \& Sauerland, U. (2019). Ineffability and unexhaustification. In Proceedings of Sinn und Bedeutung, 23(1), 399-412. https://doi.org/10.18148/sub/2019.v23i1.540.

Enguehard, É., \& Chemla, E. (2021). Connectedness as a constraint on exhaustification. Linguistics and Philosophy, 44(1), 79-112. https://doi.org/10.1007/s10988-019-09286-3.

Fox, D. (2007). Free choice and the theory of scalar implicatures. In U. Sauerland \& P. Stateva (Eds.), Presupposition and implicature in compositional semantics (pp. 71-120). London: Palgrave.

Fox, D., \& Katzir, R. (2011). On the characterization of alternatives. Natural Language Semantics, 19(1), 87-107.

Fox, D., \& Katzir, R. (2019). Modularity and iterated rationality models of scalar implicatures. Unpublished ms., MIT and University of Tel Aviv.

Fox, D., \& Spector, B. (2018). Economy and embedded exhaustification. Natural Language Semantics, $26(1), 1-50$.

Franke, M. (2011). Quantity implicatures, exhaustive interpretation, and rational conversation. Semantics \& Pragmatics, 4(1), 1-82. https://doi.org/10.3765/sp.4.1.

Gajewski, J., \& Sharvit, Y. (2012). In defense of the grammatical approach to local implicatures. Natural Language Semantics, 20(1), 31-57.

Gazdar, G. (1979). Pragmatics: Implicature, presupposition, and logical form. New York: Academic Press.

Geurts, B. (2010). Quantity implicatures. Cambridge: Cambridge University Press.

Goldstein, S. (2019). Free choice and homogeneity. Semantics \& Pragmatics, 12(23). https://doi.org/10. 3765/sp.12.23.

Grice, P. (1975). Logic and conversation. In D. Davidson \& G. Harman (Eds.), The logic of grammar (pp. 64-75). Encino, CA: Dickenson.

Groenendijk, J., \& Stokhof, M. (1984). Studies on the semantics of questions and the pragmatics of answers. University of Amsterdam dissertation.

Groenendijk, J. A. G., Janssen, T. M. V., \& Stokhof, M. B. J. (Eds.). (1984). Truth, interpretation and information: Selected papers from the third Amsterdam Colloquium. Dordrecht: Foris Publications.

Heim, I. (1991). Artikel und Definitheit. In A. von Stechow \& D. Wunderlich (Eds.), Semantik: Ein internationales Handbuch der zeitgenössischen Forschung (pp. 487-535). Berlin: de Gruyter.

Heim, I. (1992). Presupposition projection and the semantics of attitude verbs. Journal of Semantics, 9 , $183-221$.

Heim, I. (1994). Interrogative semantics and Karttunen's semantics for know. In R. Buchalla \& A. Mittwoch (Eds.), Proceedings of IATL (pp. 1128-144). Jerusalem: Hebrew University of Jerusalem.

Horn, L. (1972). On the semantic properties of logical operators in English. UCLA dissertation.

Ivlieva, N. (2013). Scalar implicatures and the grammar of plurality and disjunction. MIT dissertation.

Kamp, H. (1974). Free choice permission. Proceedings of the Aristotelian Society, 74, 57-74.

Karttunen, L., \& Peters, S. (1979). Conventional implicature. In E. Dinneen \& C.-K. Oh (Eds.), Syntax and semantics 11: Presupposition (pp. 1-56). New York: Academic Press.

Katzir, R. (2007). Structurally-defined alternatives. Linguistics and Philosophy, 30(6), 669-690.

Klinedinst, N. (2007). Plurality and possibility. UCLA dissertation.

Kratzer, A., \& Heim, I. (1998). Semantics in generative grammar. Oxford: Blackwell.

Kratzer, A., \& Shimoyama, J. (2002). Indeterminate pronouns: The view from Japanese. In Y. Otsu (Ed.), Proceedings of the Tokyo Conference on Psycholinguistics (Vol. 3, pp. 1-25). Tokyo: Hituzi Syobo.

Križ, M. (2015). Aspects of homogeneity in the semantics of natural language. University of Vienna dissertation.

Križ, M. (2016). Homogeneity, maximality, and all. Journal of Semantics, 33, 493-539.

Magri, G. (2009). A theory of individual-level predicates based on blind mandatory scalar implicatures. MIT dissertation.

Magri, G. (2011). Another argument for embedded scalar implicatures based on oddness in DE environments. Semantics \& Pragmatics, 4(6), 1-51. https://doi.org/10.3765/sp.4.6. 
Magri, G. (2014). An account for the homogeneity effects triggered by plural definites and conjunction based on double strengthening. In S. Pistoia-Reda (Ed.), Pragmatics, semantics and the case of scalar implicatures (pp. 99-145). Berlin: Springer.

Magri, G. (2017). Blindness, short-sightedness, and Hirschberg's contextually ordered alternatives: A reply to Schlenker (2012). In F. Domaneschi \& S. Pistoia-Reda (Eds.), Linguistic and psycholinguistic approaches on implicatures and presuppositions (pp. 9-54). Berlin: Springer.

Mandelkern, M. (2016). Dissatisfaction theory. Semantics and Linguistic Theory, 26, 391-416.

Marty, P. (2017). Implicatures in the DP domain. MIT dissertation.

Marty, P. (2019). On the source of proper partitivity. In Proceedings of Sinn und Bedeutung (Vol. 23).

Marty, P., \& Romoli, J. (2020). Presuppositions, implicatures, and contextual equivalence. Natural Language Semantics (to appear).

Mayr, C. (2015). Plural definite NPs presuppose multiplicity via embedded exhaustification. Semantics and Linguistic Theory, 25, 204-224.

Mayr, C., \& Romoli, J. (2016). A puzzle for theories of redundancy: Exhaustification, incrementality, and the notion of local context. Semantics \& Pragmatics, 9(7), 1-48. https://doi.org/10.3765/sp.9.7.

Meyer, M.-C. (2013). Ignorance and grammar. MIT dissertation.

Meyer, M.-C. (2014). Deriving Hurford's constraint. Semantics and Linguistic Theory, 24, 577-596.

Roberts, C. (2004). Context in dynamic interpretation. In L. R. Horn \& G. Ward (Eds.), Handbook of pragmatics (pp. 198-220). Hoboken: Blackwell Publishing.

Romoli, J. (2012). Soft but strong: Neg-raising, soft triggers, and exhaustification. Harvard University dissertation.

Romoli, J. (2013). A scalar implicature-based approach to Neg-raising. Linguistics and Philosophy, 36(4), 291-353.

Romoli, J. (2014). The presuppositions of soft triggers are obligatory scalar implicatures. Journal of Semantics, 32(2), 173-219.

Romoli, J., \& Santorio, P. (2019). Filtering free choice. Semantics \& Pragmatics, 12(12). https://doi.org/ 10.3765/sp.12.12.

Rothschild, D., \& Yablo, S. (2018). Permissive updates. MS UCL and MIT.

Rouillard, V., \& Schwarz, B. (2017). Epistemic narrowing for maximize presupposition. North East Linguistic Society, 47, 1-14.

Rouillard, V., \& Schwarz, B. (2018). Presuppositional implicatures: Quantity or maximize presupposition? Proceedings of Sinn und Bedeutung, 22(2), 289-306. https://ojs.ub.unikonstanz.de/sub/index.php/ sub/article/view/107.

Russell, B. (2006). Against grammatical computation of scalar implicatures. Journal of Semantics, 23(4), 361-382.

Santorio, P., \& Romoli, J. (2017). Probability and implicatures: A unified account of the scalar effects of disjunction under modals. Semantics \& Pragmatics, 10(13), 1-61. https://doi.org/10.3765/sp.10.13.

Sauerland, U. (2004). Scalar implicatures in complex sentences. Linguistics and Philosophy, 27(3), 367391.

Sauerland, U. (2008). Implicated presuppositions. In A. Steube (Ed.), The discourse potential of underspecified structures (pp. 581-600). Berlin: Mouton de Gruyter.

Schlenker, P. (2012). Maximize presupposition and Gricean reasoning. Natural Language Semantics, 20(4), $391-429$.

Schulz, K., \& Van Rooij, R. (2006). Pragmatic meaning and non-monotonic reasoning: The case of exhaustive interpretation. Linguistics and Philosophy, 29(2), 205-250.

Simons, M. (2001a). Disjunction and alternativeness. Linguistics and Philosophy, 24(5), 597-619.

Simons, M. (2001b). On the conversational basis of some presuppositions. Semantics and Linguistic Theory, 11, 431-448. https://doi.org/10.3765/salt.v11i0.3099.

Singh, R. (2008). Modularity and locality in interpretation. MIT dissertation.

Singh, R. (2010). Oddness and ignorance inferences. Handout presented at Modularity Reading Group at MIT.

Singh, R. (2011). Maximize presupposition! and local contexts. Natural Language Semantics, 19(2), 149_ 168.

Spector, B. (2006). Scalar implicatures: Exhaustivity and Gricean reasoning. In M. Aloni, A. Butler, \& P. Dekker (Eds.), Questions in dynamic semantics (pp. 229-254). Amsterdam: Elsevier. 
Spector, B. (2007). Aspects of the pragmatics of plural morphology: On higher-order implicatures. In U. Sauerland \& P. Stateva (Eds.), Presupposition and implicature in compositional semantics (pp. 243-281). London: Palgrave.

Spector, B., \& Sudo, Y. (2017). Presupposed ignorance and exhaustification: How scalar implicatures and presuppositions interact. Linguistics and Philosophy, 40(5), 473-517.

von Fintel, K. (1999). NPI licensing, Strawson entailment, and context dependency. Journal of Semantics, 16(2), 97-148.

von Wright, G. H. (1968). An essay in deontic logic and the general theory of action. Amsterdam: NorthHolland Publishing Company.

Willer, M. (2017). Widening free choice. In A. Cremers, T. van Gessel, \& F. Roelofsen (Eds.), Proceedings of the 21st Amsterdam Colloquium (pp. 511-520). Amsterdam: ILLC Publications.

Zweig, E. (2009). Number-neutral bare plural and the multiplicity implicature. Linguistics and Philosophy, $32,353-407$.

Publisher's Note Springer Nature remains neutral with regard to jurisdictional claims in published maps and institutional affiliations. 